\title{
ADJUSTMENT OF CREDIT PERIOD AND STOCK-DEPENDENT DEMANDS IN A SUPPLY CHAIN MODEL WITH VARIABLE IMPERFECTNESS
}

\author{
Ateka Banu ${ }^{1, *}$, Amalesh Kumar Manna ${ }^{2}$ And Shyamal Kumar Mondal ${ }^{1}$
}

\begin{abstract}
In this model, a supply chain model has been developed where a manufacturer continuously transports perfect quality items at no cost to a distribution center to maintain the market demand. At the beginning of the process, the production process is in an "in-control" state, but after a random time, it goes to an "out-of-control" state. Thus the production process produces perfect as well as imperfect items in this state. The rate of imperfect production depends on production rate and production-run length in the "out-of-control" state. The unit production cost of the manufacturer depends on the production rate which indicates that the higher production rate is the cause of higher production cost if it exceeds the normal production rate set by the manufacturer. The manufacturer provides a credit period to the distributor to increase his sales growth. In the competitive business world, credit period affects the demand rate of a retailer/buyer due to its late payment facility. So, here, credit period dependent demand function is introduced for the distributor. During the festive season, demand factor of products is usually affected by stock level. Also, for some types of products (such as clothing), the demand factor depends on its stock level. Thus we have considered stock-dependent demand function for the customers. Now, in an infinite time horizon, the problem is how they adjust their demands to sustain the whole system's financial flow. The novelty of this model is to analyze the compatibility of this two-type of demand in their businesses so that both can maintain their profits. Also, there is another credit length which is offered by the distributor. The proposed model has been discussed in type-2 fuzzy environment due to the uncertainty of the credit period. The purpose of this model is to optimize the integrated profit of the system by optimizing production rate and production-run time. Finally, numerical examples have been provided to illustrate the feasibility of both crisp and fuzzy model and some conclusions are derived conducting a sensitivity analysis of different parameters.
\end{abstract}

Mathematics Subject Classification. 90B05, 90B15, 90B25, 90B30, 90 B50.

Received October 20, 2019. Accepted April 7, 2021.

\section{INTRODUCTION}

Manufacturing sector generally uses Economic Production Model (EPQ) to optimize the objective function of the system. The concept of EPQ model was arrived in 1918 by E. W. Taft's model that was extended from the Haris's [12] Economic Order Quantity Model (EOQ). Now, in a production system, existence of defective

Keywords. Supply chain, imperfect production, two-level credit period, type-2 fuzzy environment.

1 Department of Applied Mathematics with Oceanology and Computer Programming, Vidyasagar University, Midnapore 721102, West Bengal, India.

2 Department of Mathematics, The University of Burdwan, Burdwan 713104, India.

*Corresponding author: atekabanu45@gmail.com 
items is natural phenomenon. But, in literature, there have found several research articles on EPQ model which described only the perfect items in the production system such as Goyal and Gunasekaran [11], Silver and Peterson [28], etc. However, this situation does not always hold in the real world. There are many difficulties in the manufacturing process that interrupt the process of producing the perfect items. This type of production is treated as imperfect production. In 1986, Rosenblatt and Lee [25] first time discussed the effects of imperfect production processes on EPQ model. After that Salameh and Jaber [26] also formulated an EPQ model that deals with imperfect items. Further, Hou [13] established an imperfect production model where he considered set up cost and process quality depending on capital expenditure. Again, Sana [27] proposed an EPQ model with imperfect quality items. In this paper, they have shown that the number of defective items increases with higher production rate. Recently, Manna et al. [20] developed an imperfect production model considering production rate dependent defective rate of items. Some related works on imperfect production were reported by Khan et al. [17], Taso [35], Karimi-Nasab and Sabri-Laghaie [15], Mandal and Giri [19], Manna et al. [22] and others.

Again, by literature survey, it can be found that rate of imperfect production is assumed as constant. That means, the production system starts producing imperfect items from the beginning of the process at a constant rate and the other difficulties of the system do not affect the production process. But, this phenomenon is quite impractical since some parameters like production-run time, system maintenance, higher production rate, etc. may influence a production process. Generally, for a long term production process, the machinery components' reliability gradually decreases with time. Thus it may happen that imperfect production rate increases with time. Again in a production system, there is always a limitation on the ability of the machinery system and exceeding the limitations can increase the rate of defective production. Also, the scenario of producing imperfect items from the beginning is not always true. In general, at the beginning of a production process, the system may be under control and hence, the system produces confirming items. But, after some time, machinery system can not work as the starting time. That means, the system goes out-control state with time and as a result, production of non-conforming items starts. Giri and Dohi [9] formulated an imperfect production model in which shifting time of "in-control" state to "out-of-control" state follows an arbitrary probability distribution.

Now, in an imperfect production process, screening process is necessary to differentiate perfect and imperfect ones. On literature survey, different screening process has been found. In this regard, Mandal and Giri [19] developed an imperfect production model in which they have considered $100 \%$ accurate screening process to detect the imperfect one. Also, sometime it may happen that imperfect one may be detected as a perfect one or perfect one as an imperfect one i.e., inspection error has occurred in the screening process (cf. [23]). Again, Manna et al. [20] formulated an imperfect production model in which they have considered $100 \%$ screening process but the screening rate is not equal to the production rate.

Analyzing the business systems, it is noticed that there are so many motivating tools to entice buyers like revenue sharing, trade credit, price discounts, etc. Actually, companies want to sustain the flow of their business by using these tools. On the other hand, buyers are also benefited due to these strategies. In recent business trends, credit period is marked as one of the most vital and conventional tool which generally acts as positive reinforcement. This policy influences the competitive business world in different ways. Now, buyers do not pay the purchase price instantly because of trade credit policy. So, this policy can help to overcome the situation of pricing problem of a buyer and also, it helps to earn an additional revenue by investing their sales revenue in a bank during the relaxation period. Thus it can be said that trade credit motivates buyers to collect more quantity and also, it helps to make long-term relationship between a vendor and a buyer. In this context, several research works have been made in the last few decays. In 1985, Goyal [10] developed an economic order quantity model where he first discussed the benefit of trade credit period. Again, Aggarwal and Jaggi [1] formulated a model extending Goyal's model for deteriorating items. Also, a substitute conclusion from Goyal's model was provided by Teng [36] where he proved mathematically that it creates economic sense for a well-placed purchaser to order less to take the favor of the delay payments more frequently. In Goyal's and Aggarwal's models, they considered the trade credit policy between a supplier and his customer i.e., one level trade credit policy was considered by them. Now, in an integrated system, a supplier can also provide this facility to his customer after getting trade credit from a manufacturer. That is, two-level trade credit also exists in inventory system. In this 
regard, Huang [14] first worked on two-level trade credit policy. After that Liao [18] developed an EOQ model for deteriorating items by extending Huang's model. Some relevant works on credit period were established by Dye and Ouyang [8], Chung and Cardenas-Barron [4], Das et al. [6] and Panja and Mondal [24]. Now, it is known to us that the trade credit policy is completely own choice of a manufacturer or a supplier or a retailer. So, they may connect this policy with different parameters or they may impute some conditions on it in their financial flow to figure out their motivation. For example, Das et al. [5] established an integrated supply chain model for a supplier and a retailer where procurement cost of the retailer is connected with credit period such that more credit period implies higher procurement cost for the retailer. Again, Shah and Cardenas-Barron [29] formulated a model with two-level credit period in which retailer can utilize the facility of credit period if his order quantity is greater than or equal to a specified quantity and another credit period is taken as a decision variable by the retailer. Recently, Banu and Mondal [3] established an inventory model in which they have analyzed the impact of credit period linked with warranty period of product. Hence, analyzing the above studies and literature survey on credit period, it can be concluded that a search on credit period is necessary in practical business world.

In real business world, there are some parameters that can not be defined properly and also, sometimes the parameters have a flutter from their ground. That is, these parameters are full of uncertainties. This uncertainty can be prescribed in different forms such as fuzziness or roughness or randomness. In this regard, fuzzy set theory is an important tool to handle the uncertainties. In 1991, Zimmermann [37] described the basic ideas of fuzziness and fuzzy set theory. After that, so many applications on fuzziness have been found in inventory models such as Taleizadeh et al. [34], Das et al. [7], Kazemi et al. [16], Shekarian et al. [32,33], Manna et al. [21], Banu and Mondal [2], etc. In this concern, there is no specific rules to assign the value of the parameter credit period so that it may helpful for a system. So, it may be vague in nature. Reviewing the literatures, it is noticed that most of the cases, fuzziness of the parameter credit period is tackled in type- 1 fuzzy scenario. But, fuzziness of a parameter can be found in type-2 fuzzy scenario. Till now, there is only a few search on credit period in type-2 fuzzy sense such as Panja and Mondal [24]. Thus, search with type-2 fuzzy credit period is important in inventory model to study the effects of credit period in fuzzy environment.

Discussing the above phenomena of a production model and summarizing the outcomes, in this proposed model, we have considered a supply chain between a manufacturer and a distributor. The manufacturer's production system is an imperfect production system. After a random time, the production system goes to "out-of-control" state. In this production system, the manufacturer produces items at a variable rate and the rate of imperfect production in "out-of-control" state varies with production rate and production-run time. So, to sort out the imperfect ones, screening process starts at the beginning of the production process and continues up-to the end of the production process. During the screening process, it is seen that some produced imperfect items are reworkable and these are reworked immediately. The rework process is error-free, i.e., all reworked items are of perfect quality $(c f .[30,31])$. Also, a percentage of imperfect items are treated as less perfect items and these are sold out to another wholesaler in a single lot at the end of the production process. And the remaining portion of the imperfect items can't be usable which are marked as disposal items.

In this model, the manufacturer continuously transports the perfect quality items to the distribution center at no cost according to the distributer's demand rate so that the distributor always can maintain his stock to provoke buyers. The manufacturer takes a strategy to give credit length for the total delivered quantity to the distributor. In this competitive era, trade credit or credit period policy plays an important role in deciding about an inventory because a retailer/a buyer has not to pay for the purchase amount instantly. Also, it acts as a promotional tool that attracts more customers. Due to this facility, a retailer/buyer may collect more items whenever it has market demand. So, we have considered demand function of the distributor depending on the credit length given by the manufacturer. Again it can be seen that the demand rate of some products (e.g. garments) or products during the festive season depends on the stock level as buyers get the opportunity to pick more products as well as pick their preferred products. The stock of more items can impress buyers with the idea of freshness or the latest collection. Also, in recent years, online shopping has become a trend. In this case, the displayed stock level impresses the buyer as a buyer can easily compare the design, color, etc. of the 
TABLE 1. A comparison of the present article with some existing models.

\begin{tabular}{|c|c|c|c|c|c|c|c|}
\hline Authors & $\begin{array}{l}\text { Imperfect } \\
\text { production }\end{array}$ & $\begin{array}{l}\text { Production rate and } \\
\text { time-dependent } \\
\text { defective rate }\end{array}$ & Rework & $\begin{array}{l}\text { Stock- } \\
\text { dependent } \\
\text { demand }\end{array}$ & $\begin{array}{l}\text { Trade } \\
\text { credit } \\
\text { policy }\end{array}$ & $\begin{array}{l}\text { Type- } 2 \text { fuzzy } \\
\text { credit period }\end{array}$ & $\begin{array}{l}\text { Supply } \\
\text { chain }\end{array}$ \\
\hline Giri and Dohi [9] & $\sqrt{ }$ & & & & & & \\
\hline Sana [27] & $\sqrt{ }$ & $\sqrt{ }$ & $\sqrt{ }$ & & & & \\
\hline $\begin{array}{l}\text { Shekarian et al. [30, } \\
31]\end{array}$ & $\sqrt{ }$ & & $\sqrt{ }$ & & & & \\
\hline $\begin{array}{l}\text { Karimi-Nasab and } \\
\text { Sabri-Laghaie [15] }\end{array}$ & $\sqrt{ }$ & & $\sqrt{ }$ & & & & \\
\hline Taso [35] & $\sqrt{ }$ & & & & $\sqrt{ }$ & & $\sqrt{ }$ \\
\hline Das et al. $[5-7]$ & & & & & $\sqrt{ }$ & & $\sqrt{ }$ \\
\hline $\begin{array}{l}\text { Banu and Mondal } \\
{[2]}\end{array}$ & & & & & $\sqrt{ }$ & & \\
\hline Shah and & & & & & $\sqrt{ }$ & & \\
\hline $\begin{array}{l}\text { Cardenas-Barron } \\
\text { [29] }\end{array}$ & & & & & & & \\
\hline $\begin{array}{l}\text { Mandal and Giri } \\
\text { [19] }\end{array}$ & $\sqrt{ }$ & & & $\sqrt{ }$ & & & $\sqrt{ }$ \\
\hline $\begin{array}{l}\text { Manna et al. } \\
{[20]}\end{array}$ & $\sqrt{ }$ & & & & & & \\
\hline Manna et al. [21] & $\sqrt{ }$ & $\sqrt{ }$ & $\sqrt{ }$ & $\sqrt{ }$ & $\sqrt{ }$ & & $\sqrt{ }$ \\
\hline $\begin{array}{l}\text { Panja and Mondal } \\
{[24]}\end{array}$ & $\sqrt{ }$ & $\sqrt{ }$ & & & $\sqrt{ }$ & $\sqrt{ }$ & $\sqrt{ }$ \\
\hline Present article & $\sqrt{ }$ & $\sqrt{ }$ & $\sqrt{ }$ & $\sqrt{ }$ & $\sqrt{ }$ & $\sqrt{ }$ & $\sqrt{ }$ \\
\hline
\end{tabular}

product due to more stock. Thus, it can be said that the higher the stock level, the more the buyers will be interested in buying the product, and more buyers will have the opportunity to get the product at the same time. That means, more stocks of items may increase the demand in the market $(c f .[19,21])$. So, here, we have incorporated stock-dependent demand for the customers. Now, due to stock-dependent demand, it is obvious that more stocks of items implies more sales revenues for both of them. But, the question is how long they will continue their businesses. The novelty of this model is to analyze of adjustment of the credit period and stock-dependent demands so that both will be profitable. Again, in this scenario, both the manufacturer and the distributor if collaborate with each other by discussing their strategies, then it may be helpful for both of them and also for the whole system. Thus in this article, we have discussed the model in an integrated approach. In real business system, sometimes it happens that a manufacturer cannot increase the selling price of an item due to the reluctance of the customers to buy at a higher price though its production cost is variable. Then, the manufacturer has to sell the items by comparing them to the market price. According to this fact, here, the selling price of the items has been considered as fixed for the manufacturer. Due to uncertainty of the real business world, the credit period of the distributor has been considered in type-2 fuzzy scenario. Also, this study considers that there exists another credit length which is offered by the distributor. In his business process, the distributor provides a specified period in such a way that customers arriving within this period pay for the purchase amount at the end of the period. After this period, buyers will have to pay at time of purchase. Considering the above assumptions in integrating approach, the objective of this model is to optimize the integrated profit of the system and the total business cycle length by optimizing the production rate and the production run time of the manufacturer. After reviewing the above literatures, the contribution of this paper has been highlighted in Table 1 comparing the other articles under various conditions.

The rest of the paper is structured as follows: Section 2 provides the adequate notations and assumptions to formulate the model; Section 3 describes the problem and gives formulation of the crisp model; Section 4 
describes formulation of the fuzzy model; Section 5 illustrates the numerical examples both for the crisp and fuzzy model; Section 6 gives a sensitivity analysis to draw managerial insights; Section 7 finally presents some conclusions and future scopes.

\section{NotATion AND ASSUMPTIONS}

The following notation and assumptions have been used in the development of the proposed model.

\subsection{Notation}

The following notations are used to formulate the proposed model:

\begin{tabular}{|c|c|c|}
\hline$q_{1 m}(t)$ & $:$ & Inventory level at time $t$ of perfect quality items for manufacturer. \\
\hline$q_{2 m}(t)$ & : & Inventory level at time $t$ of imperfect quality items for manufacturer. \\
\hline$q_{r}(t)$ & : & Inventory level at time $t$ of perfect quality items for distributor. \\
\hline$P$ & : & Production rate in units (decision variable). \\
\hline$P_{0}$ & : & Normal production rate of the production system. \\
\hline$\beta$ & : & Rate of producing imperfect quality items in "out-of-control state". \\
\hline$\delta$ & : & Rate of reworked of imperfect items. \\
\hline$\tau$ & : & $\begin{array}{l}\text { An exponential random variable with mean } \frac{1}{\lambda} \text { and denotes the time at which the } \\
\text { production system shifts from "in-control" state to the "out-of-control" state. }\end{array}$ \\
\hline$f(\tau)$ & : & Probability density function of $\tau$. \\
\hline & : & Percentage of disposal items of produce items. \\
\hline$(1-\gamma)$ & : & $\begin{array}{l}\text { Percentage of produced imperfect items which are not reworked as a perfect item and } \\
\text { these are sold through reduce selling price. }\end{array}$ \\
\hline$D_{r}$ & : & Demand rate of perfect quality items for distributor. \\
\hline$D_{c}$ & : & Demand rate of perfect quality items for customer. \\
\hline$t_{1}$ & : & Production-run time in one period (decision variable). \\
\hline$t_{2}$ & : & Manufacturer's business period. \\
\hline$T$ & : & Total business time in one period. \\
\hline$M$ & : & Credit period offered by manufacturer. \\
\hline$Q_{m}$ & $:$ & Total produced items of manufacturer. \\
\hline$Q_{r}$ & $:$ & Lot-size of perfect quality items. \\
\hline$c_{d}$ & : & Disposal cost per unit item. \\
\hline$s_{c}$ & : & Screening cost per unit item. \\
\hline$A_{m}$ & : & Set up cost of manufacturer. \\
\hline$h_{m}$ & $:$ & Holding cost per unit for per unit time for perfect item of manufacturer. \\
\hline$h_{m}^{\prime}$ & : & Holding cost per unit for per unit time for imperfect item of manufacturer. \\
\hline$r_{c m}$ & $:$ & Reworking cost per unit item for manufacturer. \\
\hline$c_{p}$ & $:$ & Production cost per unit item. \\
\hline$s_{m}$ & : & Selling price per unit of perfect quality items for manufacturer. \\
\hline$s_{m}^{\prime}$ & $:$ & Selling price per unit less perfect quality items for manufacturer. \\
\hline$A_{r}$ & : & Set up cost of distributor. \\
\hline$h_{r}$ & : & Holding cost per unit for per unit time of perfect quality items of distributor. \\
\hline & $:$ & Selling price per unit of perfect quality items of distributor. \\
\hline$E\left[\Pi_{m}\left(P, t_{1}\right)\right]$ & $:$ & Expected total profit of manufacturer. \\
\hline$\Pi_{r}^{(i)}$ & $:$ & Total profit of distributor, where $i=1,2,3$ refers different cases. \\
\hline$E\left[\operatorname{ITP}\left(P, t_{1}\right)\right]$ & $:$ & Expected total profit of the integrated system. \\
\hline
\end{tabular}




\subsection{Assumptions}

The following assumptions are made throughout the paper to formulate the model.

(i) The manufacturer produces perfect as well as imperfect quality items. Some portion of imperfect items are reworked as a perfect quality items. Manufacturer continuously transports the perfect quality items to a distribution center at no cost and from there, the owner of the center sells the items to several buyers.

(ii) The total planning horizon is infinite.

(iii) Production rate $(P)$ and the production-run time $\left(t_{1}\right)$ are considered as decision variable.

(iv) In general, at the starting time of a production process, the system is in "in-control" state. That means, the system produces good quality items and after some time, it shifts to "out-of-control" state. In this state, the system produces perfect as well as imperfect quality items. If we focus on a manufacturing system, we will find many factors that lead to the production of defective items such as bad raw materials, lack of laborer's experience, high production rate, machining component, long run production time, etc. So, it can be said that the time of occupancy of "out-of-control" state can't be predicted. In this model, this shifting time $(\tau)$ is assumed as a random variable.

(v) If a manufacturing system produces items with a high production rate and the process continues for a long time, then both higher production rate and production-run time break down the efficiency of the machinery system and increase the rate of imperfect production. So, for a long run process, if "out-ofcontrol" state occurs at very beginning then the system produces more non-confirming items in the rest time. Therefore, rate of producing imperfect items $(\beta)$ has been considered depending on production rate $(P)$ and time length $(t-\tau)$ in the "out-of-control" state as follows:

$$
\beta= \begin{cases}0, & 0 \leq t \leq \tau \\ \eta P^{\nu}(t-\tau)^{\xi}, & \tau \leq t \leq t_{1}\end{cases}
$$

where $\nu \geq 0$ and $\xi \geq 0$ and $\eta>0$ is the imperfect production rate when $\nu \rightarrow 0$ and $\xi \rightarrow 0$. From the above expression, it is reflected that for a constant production rate $P, \beta$ is minimum when $\tau \rightarrow t_{1}$ and maximum when $\tau \rightarrow 0$.

(vi) The production cost per unit item has been considered as a sum of a fixed cost and a variable cost which depends on production rate. Normally, a manufacturing company produces products at a normal rate looking at the market normal demand. Also, the company spends a basic cost for the purpose of buying raw materials, laborers' salary, a normal maintenance cost, etc. But, if the company increases the production rate than the normal rate then the company has to give more effort to maintenance than previous and also the wear-tear cost may increase. As a result, the company has to pay an extra charges due to high production rate. Thus, here the production cost per unit item has been assumed as $c_{p}=c_{p_{1}}+\mu\left(P-P_{0}\right)^{b}$, where first part is the fixed cost and the second part is the variable cost. Here, $P_{0}$ is the normal production rate of the manufacturer and $\mu(>0)$ is the cost effective parameter and $b$ is a positive constant refers the affection parameter due to excess production rate than the normal range.

Lemma 2.1. The production cost $c_{p}$ increases with respect to production rate $P$ at a increasing rate for $b>1$, or increases at a decreasing rate for $b<1$.

Proof. From the above expression of production cost, it is concluded that the production cost is constant for the production rate $P_{0}$ or less.

Now, $\frac{\mathrm{d} c_{p}}{\mathrm{~d} P}=\mu b\left(P-P_{0}\right)^{(b-1)}>0$ as $\mu>0$ and $b>0$.

This nature concludes that production cost for per unit item increases with increasing value of production rate $P\left(P>P_{0}\right)$.

Again, 

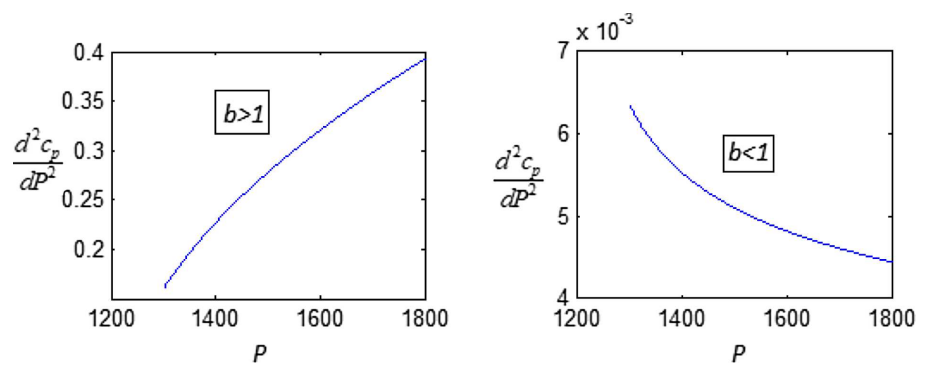

Figure 1. Rate of change of $c_{p}$ w.r.t $P$.

$$
\begin{aligned}
\frac{\mathrm{d}^{2} c_{p}}{\mathrm{~d} P^{2}} & =\mu b(b-1)\left(P-P_{0}\right)^{(b-2)} \\
& >0 ; \quad \text { if } b>1 \\
& <0 ; \quad \text { if } b<1 .
\end{aligned}
$$

This shows that the production cost $c_{p}$ increases with respect to production rate $P\left(P>P_{0}\right)$ at a increasing rate for $b>1$ or it increases at a decreasing rate for $b<1$ (Fig. 1).

(vii) Looking at the today's business world, it can be said that facility of credit period always has good sign in a buyer's mind and also this facility makes a long-term relation between a buyer and a vendor. In this regard, the manufacturer assumes a policy to give a credit period $(M)$ to the distributor in such a way that the distributor must pay for the total delivered quantity at the end of the credit period where length of the credit period must be within the total business period of the system. The offered credit period have been discussed in crisp and type-2 fuzzy scenario in our model.

(viii) In this competitive business market, trade credit facility has become a powerful promotional tool that encourages a buyer to buy more. Therefore, the distributor may want to increase his demand by getting the credit period facility whenever the product has demand. Incorporating this idea, the distributor's demand rate is considered in the form $D_{r}=D_{0} e^{\alpha M}$, where $D_{0}$ is the normal demand rate of the distributor when there is no effect of the credit period and $\alpha(\geq 0)$ is the effectiveness parameter for credit period i.e., $\alpha$ measures how the credit period influences the distributor's financial flow. This fact also impresses the manufacturer to offer more credit period for delivering more quantities.

(ix) Although the distributor's payment time is at the end of his credit period, he wants to pay for the purchase amount at the end of his business period to avoid the situation of taking bank loan and also to earn more interest. He has to pay interest at a rate $I_{p}$ to the manufacturer due to late payment.

(x) In business system, in general, all marketable products have a constant market demand. Again it may depend on time and/or initial stock or on-hand inventory. Sometimes (during the festive season), it is seen that the sale of a product depends on its stock level. Also, there are some types of products (such as garments) for which more stocks have a good effect on buyers as they have the opportunity to collect more as well as pick their own desired products. Thus, stock levels play a significant role in increasing the demand for a product. In that sense, we have considered the stock-dependent demand function for customers here. The demand rate of the customers $D_{c}$ is assumed as $D_{c}=d_{0}+d_{1} q_{r}(t)$, where $d_{0}>0$ is the initial demand rate and $0 \leq d_{1}<1$ is the stock sensitivity parameter of the demand.

(xi) The distributor also provides credit period facility within a specified period $[0, N]$ to establish a long-term relationship with his/her customers. In this case, buyers who arrive during the $[0, N]$ period, pay for their purchase amount at $N(<M)$. Thus, it can be said that instead of a certain credit length, buyers get different credit lengths according to their arrival. Also, due to this period he can publicize his business among more buyers. 


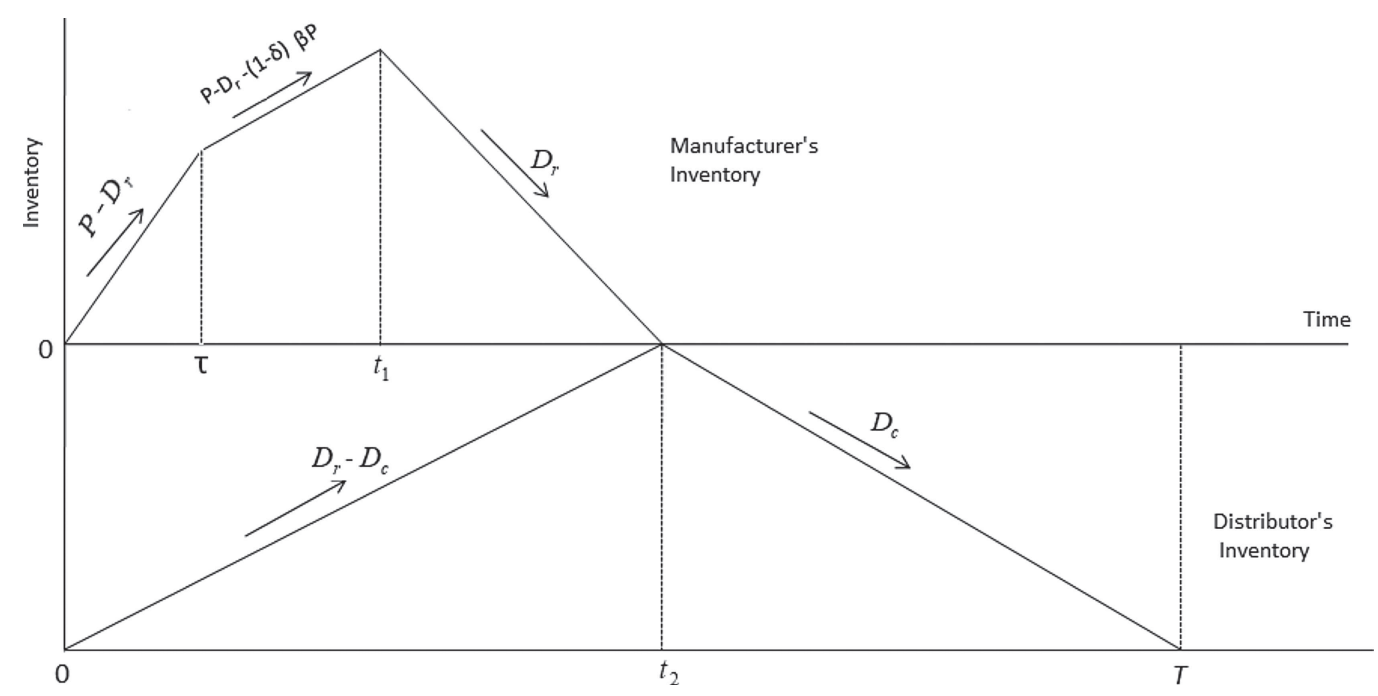

FIGURE 2. Inventory of perfect quality items.

\section{Problem Description AND MOdel Formulation}

\subsection{Problem description}

This article presents an imperfect production inventory model comprising a manufacturer and a distributor. The production process starts with production rate $P$ and continues during the time period $\left[0, t_{1}\right]$. The production system undergoes in an "out-of-control" state after a random time $\tau$ which may occur during regular production-run time. In "out-of-control" state, the system produces imperfect items at a rate $\beta$. Hence, the manufacturer bears a cost $s_{c}$ per unit item for screening purpose during the period $\left[0, t_{1}\right]$. During the screening process, the defective (imperfect) items which are produced during regular production-run time are sent to factory for rework at a rate of $\delta$. Comparing the value of produced items, the manufacturer sales the perfect items at a price $s_{m}$ per unit to the distributor. After the screening process, it is seen that $\gamma$ percentage of defective items are not usable and these are considered as disposal items and the remaining less defective items are sold to an another wholesaler in a single lot at a price $s_{m}^{\prime}\left(<s_{m}\right)$ per unit item at the end of the production process. The inventory level of the manufacturer becomes zero at time $t=t_{2}$. In this process, the lot-size of the perfect items that is delivered to the distributer is $Q_{r}$ and the total produced items of the manufacturer is $Q_{m}$. Here, it is taken into account that inventory holding cost per unit of perfect items is much more than the holding cost of imperfect items. It is also taken into account that the manufacturer gives opportunity to take facility of credit period $(M(<T))$ to the distributor to increase the demand and also to create a long-term relationship between them. As a result, the manufacturer spends a cost for opportunity loss at a rate of $I_{c}$ per unit per year. After receiving the items from the manufacturer, the distributer sells the perfect quantity of items during the time period $[0, T]$ to his customers at a price $s_{r}$ per unit item. The distributor also offers credit period facility to his customers during the period $[0, N]$ such that all customers who get the facility must have to pay their payable amounts within $N(<M)$. Description of inventory level for perfect quality items are depicted in Figure 2 for both the manufacturer and the distributor.

\subsection{Model formulation for the manufacturer}

At the beginning of the production process, the system is assumed to be in "in-control" state. After a random time $\tau$ which follows exponential probability distribution with mean $\frac{1}{\lambda}$, the system may shift to an 
"out-of-control" state and may generate non-conforming quality items. So, in our production system, two cases may arise:

\subsubsection{Case I: when $0<\tau<t_{1}$ the "out-of-control" state occurs during regular production-run time}

As $\tau$ occurs in the time span $\left(0, t_{1}\right)$, the system produces good quality items during $(0, \tau]$ and it produces both good and defective (imperfect items) items during $\left[\tau, t_{1}\right)$. The total produced items during $\left[0, t_{1}\right]$ are used to meet the demand of the distributor up-to time $t_{2}$.

\section{For perfect quality items of the manufacturer:}

The rate of change of inventory level of manufacturer for perfect quality items can be represented by the following differential equations:

$$
\frac{\mathrm{d} q_{1 m}}{\mathrm{~d} t}= \begin{cases}P-D_{r}, & 0 \leq t \leq \tau \\ P-D_{r}-(1-\delta) \beta P, & \tau \leq t \leq t_{1} \\ -D_{r}, & t_{1} \leq t \leq t_{2}\end{cases}
$$

with boundary conditions $q_{1 m}(0)=0, q_{1 m}(\tau)=\left(P-D_{r}\right) \tau$ and $q_{1 m}\left(t_{2}\right)=0$.

The solution of above differential equations are given by

$$
q_{1 m}(t)= \begin{cases}\left(P-D_{r}\right) t, & 0 \leq t \leq \tau \\ \left(P-D_{r}\right) t-(1-\delta) \eta P^{\nu+1} \frac{(t-\tau)^{\xi+1}}{\xi+1}, & \tau \leq t \leq t_{1} \\ D_{r}\left(t_{2}-t\right), & t_{1} \leq t \leq t_{2}\end{cases}
$$

Lemma 3.1. The manufacturer's production time period $\left(t_{1}\right)$ and production rate $(P)$ must satisfy the condition $P t_{1}-(1-\delta) \eta P^{\nu+1} \frac{\left(t_{1}-\tau\right)^{\xi+1}}{\xi+1}=D_{r} t_{2}$.

Proof. From the continuity conditions of $q_{1 m}(t)$ at $t=t_{1}$, the following is obtained,

$$
\begin{gathered}
\left(P-D_{r}\right) t_{1}-(1-\delta) P^{\nu+1} \eta \frac{\left(t_{1}-\tau\right)^{\xi+1}}{\xi+1}=D_{r}\left(t_{2}-t_{1}\right) \\
\Rightarrow P t_{1}-(1-\delta) \eta P^{\nu+1} \frac{\left(t_{1}-\tau\right)^{\xi+1}}{\xi+1}=D_{r} t_{2} .
\end{gathered}
$$

Hence the proof.

Reworking Cost (RCM) for the manufacturer is:

$$
\mathrm{RCM}=r_{c m} \int_{\tau}^{t_{1}} \delta \beta P \mathrm{~d} t=r_{c m} \delta P^{\nu+1} \int_{\tau}^{t_{1}} \eta(t-\tau)^{\xi} \mathrm{d} t=\frac{r_{c m} \delta \eta}{\xi+1} P^{\nu+1}\left(t_{1}-\tau\right)^{\xi+1}
$$

Inventory holding cost $\left(\mathrm{HCM}_{1}\right)$ for perfect items is:

$$
\begin{aligned}
\mathrm{HCM}_{1} & =h_{m}\left[\int_{0}^{\tau} q_{1 m}(t) \mathrm{d} t+\int_{\tau}^{t_{1}} q_{1 m}(t) \mathrm{d} t+\int_{t_{1}}^{t_{2}} q_{1 m}(t) \mathrm{d} t\right] \\
& =h_{m}\left[\int_{0}^{\tau}\left(P-D_{r}\right) t \mathrm{~d} t+\int_{\tau}^{t_{1}}\left\{\left(P-D_{r}\right) t-(1-\delta) \eta P^{\nu+1} \frac{(t-\tau)^{\xi+1}}{\xi+1}\right\} \mathrm{d} t+\int_{t_{1}}^{t_{2}} D_{r}\left(t_{2}-t\right) \mathrm{d} t\right] \\
& =\frac{h_{m}}{2}\left[\left(P-D_{r}\right) t_{1}^{2}-\frac{2(1-\delta) \eta}{(\xi+1)(\xi+2)} P^{\nu+1}\left(t_{1}-\tau\right)^{\xi+2}+D_{r}\left(t_{2}-t_{1}\right)^{2}\right] .
\end{aligned}
$$

The manufacturer gives a relaxation period $(M)$ to the distributor. Obviously, the manufacturer will be deprived from the benefit of the interest for the sold out items. Here, it is considered that the manufacturer losses interest at a rate of $I_{c}$ per unit per year. Therefore, the opportunity cost of the manufacturer is $=s_{m} I_{c} M D_{r} t_{2}$. 


\section{For less imperfect quality items of the manufacturer:}

The rate of change of inventory level of the manufacturer for imperfect quality items can be represented by the following differential equation

$$
\frac{\mathrm{d} q_{2 m}}{\mathrm{~d} t}=(1-\gamma)(1-\delta) \beta P, \tau \leq t \leq t_{1}
$$

with the condition $q_{2 m}(\tau)=0$.

The solution of above differential equation is given by

$$
q_{2 m}(t)=(1-\gamma)(1-\delta) \eta P^{\nu+1} \frac{(t-\tau)^{\xi+1}}{\xi+1}, \tau \leq t \leq t_{1}
$$

Inventory holding cost for imperfect items is equal to

$$
\begin{aligned}
\mathrm{HCM}_{2} & =h_{m}^{\prime} \int_{\tau}^{t_{1}} q_{2 m}(t) \mathrm{d} t \\
& =h_{m}^{\prime} \int_{\tau}^{t_{2}}(1-\gamma)(1-\delta) \eta P^{\nu+1} \frac{(t-\tau)^{\xi+1}}{\xi+1} \mathrm{~d} t \\
& =\frac{h_{m}^{\prime}(1-\gamma)(1-\delta) \eta}{(\xi+1)(\xi+2)} P^{\nu+1}\left(t_{1}-\tau\right)^{\xi+2} .
\end{aligned}
$$

Production cost for the manufacturer $=c_{p} P t_{1}$.

Inspection cost for the screening purpose during the production time is $=s_{c} P t_{1}$.

Set up cost of the manufacturer $=A_{m}$.

Revenue of perfect quality items for the manufacturer $=s_{m} D_{r} t_{2}$.

Revenue of less imperfect quality items for the manufacturer $=s_{m}^{\prime}(1-\gamma)(1-\delta) \eta P^{\nu+1} \frac{\left(t_{1}-\tau\right)^{\xi+1}}{(\xi+1)}$.

\section{Amount of disposal items:}

The inventory level of the disposal amount during the period $\left[0, t_{1}\right]$ is given by

$$
q_{3 m}(t)=\gamma(1-\delta) \eta P^{\nu+1} \frac{(t-\tau)^{\xi+1}}{\xi+1}, \quad \tau \leq t \leq t_{1} .
$$

Total disposal amounts during $[0, T]=\gamma(1-\delta) \eta P^{\nu+1} \frac{\left(t_{1}-\tau\right)^{\xi+1}}{(\xi+1)}$.

Hence, the manufacturer has to bear some cost for the disposal items. $c_{d}$ is the cost per unit item for this purpose. Therefore, the total disposal cost of the manufacturer is $=c_{d} \gamma(1-\delta) \eta P^{\nu+1} \frac{\left(t_{1}-\tau\right)^{\xi+1}}{(\xi+1)}$.

In this case, total expected profit $E\left[\Pi_{m 1}\left(P, t_{1}\right)\right]$ of the manufacturer during the period $[0, T]$ is given by

$$
\begin{aligned}
E\left[\Pi_{m 1}\left(P, t_{1}\right)\right]= & \left\{s_{m} D_{r} t_{2}-\left(c_{p}+s_{c}\right) P t_{1}-A_{m}-s_{m} I_{c} M D_{r} t_{2}\right\} \\
& +\left\{\left\{s_{m}^{\prime}(1-\gamma)-c_{d} \gamma\right\}(1-\delta)-r_{c m} \delta\right\} \frac{\eta P^{\nu+1}}{(\xi+1)} E\left[\left(t_{1}-\tau\right)^{\xi+1}\right] \\
& -\frac{h_{m}}{2}\left[\left(P-D_{r}\right) t_{1}^{2}+D_{r}\left(t_{2}-t_{1}\right)^{2}\right]-\left\{h_{m}^{\prime}(1-\gamma)-h_{m}\right\} \frac{(1-\delta) \eta P^{\nu+1}}{(\xi+1)(\xi+2)} E\left[\left(t_{1}-\tau\right)^{\xi+2}\right] .
\end{aligned}
$$

3.2.2. Case II: when $t_{1} \leq \tau<\infty$, the "out-of-control" state does not occur within the production-run time

In this case, no "out-of-control" state occurs during production-run time. Then governing differential equations of the inventory system are given as follows: 
For perfect quality items of the manufacturer:

$$
\frac{\mathrm{d} q_{1 m}}{\mathrm{~d} t}= \begin{cases}P-D_{r}, & 0 \leq t \leq t_{1} \\ -D_{r}, & t_{1} \leq t \leq t_{2}\end{cases}
$$

with boundary conditions $q_{1 m}(0)=0$, and $q_{1 m}\left(t_{2}\right)=0$.

The solution of above differential equations are given by

$$
q_{1 m}= \begin{cases}\left(P-D_{r}\right) t, & 0 \leq t \leq t_{1} \\ D_{r}\left(t_{2}-t\right), & t_{1} \leq t \leq t_{2} .\end{cases}
$$

Inventory holding cost for perfect items is equal to

$$
\begin{aligned}
\mathrm{HCM}_{1} & =h_{m}\left[\int_{0}^{t_{1}} q_{1 m}(t) \mathrm{d} t+\int_{t_{1}}^{t_{2}} q_{1 m}(t) \mathrm{d} t\right] \\
& =h_{m}\left[\int_{0}^{t_{1}}\left(P-D_{r}\right) t \mathrm{~d} t+\int_{t_{1}}^{t_{2}} D_{r}\left(t_{2}-t\right) \mathrm{d} t\right] \\
& =\frac{h_{m}}{2}\left[\left(P-D_{r}\right) t_{1}^{2}+D_{r}\left(t_{2}-t_{1}\right)^{2}\right] .
\end{aligned}
$$

The manufacturer gives a relaxation period $(M)$ to the distributor. Obviously, the manufacturer will be deprived from the benefit of the interest for the sold out items. Here, it is considered that the manufacturer losses interest at a rate of $I_{c}$ per unit per year. Therefore, the opportunity cost of the manufacturer is $=s_{m} I_{c} M D_{r} t_{2}$.

Production cost for the manufacturer $=c_{p} P t_{1}$.

Inspection cost amount is $=s_{c} P t_{1}$.

Set up cost of the manufacturer $=A_{m}$.

Revenue of perfect quality items for the manufacturer $=s_{m} D_{r} t_{2}$.

In this case, total expected profit $E\left[\Pi_{m 2}\left(P, t_{2}\right)\right]$ of the manufacturer during the period $[0, T]$ is given by

$$
\begin{aligned}
E\left[\Pi_{m 2}\left(P, t_{1}\right)\right]= & \left\{s_{m} D_{r} t_{2}-\left(c_{p}+s_{c}\right) P t_{1}-A_{m}-s_{m} I_{c} M D_{r} t_{2}\right\} \int_{t_{1}}^{\infty} f(\tau) \mathrm{d} \tau \\
& -\frac{h_{m}}{2} \int_{t_{1}}^{\infty}\left\{\left(P-D_{r}\right) t_{1}^{2}+D_{r}\left(t_{2}-t_{1}\right)^{2}\right\} f(\tau) \mathrm{d} \tau .
\end{aligned}
$$

Lemma 3.2. The manufacturer's expected time period of inventory $\left(t_{2}\right)$ is given by

$$
t_{2}=\frac{P t_{1}}{D_{r}}-\frac{(1-\delta) \eta P^{\nu+1}}{(\xi+1) D_{r}} \int_{0}^{t_{1}}\left(t_{1}-\tau\right)^{\xi+1} \mathrm{~d} t
$$

Proof. From the continuity conditions of $q_{1 m}(t)$ at $t=t_{1}$, when $0 \leq \tau \leq t_{1}$ we have

$$
t_{2}=\frac{P t_{1}}{D_{r}}-\frac{(1-\delta) \eta P^{\nu+1}}{(\xi+1) D_{r}}\left(t_{1}-\tau\right)^{\xi+1} .
$$

In this case, expected value of $t_{2}$ is given by

$$
\int_{0}^{t_{1}} t_{2} f(\tau) \mathrm{d} \tau=\int_{0}^{t_{1}} \frac{P t_{1}}{D_{r}} f(\tau) \mathrm{d} \tau-\int_{0}^{t_{1}} \frac{(1-\delta) \eta P^{\nu+1}}{(\xi+1) D_{r}}\left(t_{1}-\tau\right)^{\xi+1} f(\tau) \mathrm{d} \tau .
$$


From the continuity conditions of $q_{1 m}(t)$ at $t=t_{1}$, when $t_{1} \leq \tau<\infty$ we have, $t_{2}=\frac{P t_{1}}{D_{r}}$. For this case, expected value of $t_{2}$ is given by

$$
\int_{t_{1}}^{\infty} t_{2} f(\tau) \mathrm{d} \tau=\int_{t_{1}}^{\infty} \frac{P t_{1}}{D_{r}} f(\tau) \mathrm{d} \tau
$$

Since the above two events are mutually exclusive, therefore expected value of $t_{2}$ is given by

$$
t_{2}=\frac{P t_{1}}{D_{r}}-\frac{(1-\delta) \eta P^{\nu+1}}{(\xi+1) D_{r}} \int_{0}^{t_{1}}\left(t_{1}-\tau\right)^{\xi+1} \mathrm{~d} \tau
$$

Now combining Case I and Case II and from equations (3.4) and (3.7), the expected profit of the manufacturer $E\left[\Pi_{m}\left(P, t_{1}\right)\right]$ during the business period is equal to

$$
\begin{aligned}
E\left[\Pi_{m}\left(P, t_{1}\right)\right]= & {\left[\left\{s_{m} D_{r} t_{2}-\left(c_{p}+s_{c}\right) P t_{1}-A_{m}-s_{m} I_{c} M D_{r} t_{2}\right\}-\frac{h_{m}}{2}\left\{\left(P-D_{r}\right) t_{1}^{2}+D_{r}\left(t_{1}-t_{2}\right)^{2}\right\}\right] } \\
& +\left\{\left\{s_{m}^{\prime}(1-\gamma)-c_{d} \gamma\right\}(1-\delta)-r_{c m} \delta\right\} \int_{0}^{t_{1}} \eta P^{\nu+1} \frac{\left(t_{1}-\tau\right)^{\xi+1}}{(\xi+1)} f(\tau) \mathrm{d} \tau \\
& -\left\{h_{m}^{\prime}(1-\gamma)-h_{m}\right\} \int_{0}^{t_{1}} \frac{\eta(1-\delta) P^{\nu+1}}{(\xi+1)(\xi+2)}\left(t_{1}-\tau\right)^{\xi+2} f(\tau) \mathrm{d} \tau .
\end{aligned}
$$

Now, for $\xi \neq 0$, the imperfect production rate $(\beta)$ depends on both the production rate and the productionrun length in the "out-of-control" state (assumption v). Here, we have considered value of $\xi=1$. This value implies that the rate of imperfect production $\beta$ linearly depends on $(t-\tau)$. Otherwise, $\beta$ depends on $(t-\tau)$ non-linearly. Therefore, taking $\xi=1$, the necessary approximation to find out the value of the expected profit of the manufacturer in shown in Appendix D.

Therefore, the expected profit of the manufacturer becomes

$$
\begin{aligned}
E\left[\Pi_{m}\left(P, t_{1}\right)\right] \simeq & {\left[\left\{s_{m} D_{r} t_{2}-\left(c_{p}+s_{c}\right) P t_{1}-A_{m}-s_{m} I_{c} M D_{r} t_{2}\right\}-\frac{h_{m}}{2}\left\{\left(P-D_{r}\right) t_{1}^{2}+D_{r}\left(t_{1}-t_{2}\right)^{2}\right\}\right] } \\
& +\left\{\left\{s_{m}^{\prime}(1-\gamma)-c_{d} \gamma\right\}(1-\delta)-r_{c m} \delta\right\} \eta P^{\nu+1} \lambda \frac{t_{1}^{3}}{6}-\left\{h_{m}^{\prime}(1-\gamma)-h_{m}\right\} \frac{\eta(1-\delta) \lambda P^{\nu+1}}{24} t_{1}^{4} .
\end{aligned}
$$

\subsection{Model formulation for the distributor}

After receiving the items from the manufacturer, the distributor fulfils customers' demand by the perfect quality items. The rate of change of on hand inventory of perfect quality items are given by

$$
\frac{\mathrm{d} q_{r}(t)}{\mathrm{d} t}= \begin{cases}\left(D_{r}-D_{c}\right), & 0 \leq t \leq t_{2} \\ -D_{c}, & t_{2} \leq t \leq T\end{cases}
$$

with boundary conditions $q_{r}(0)=0$ and $q_{r}(T)=0$.

Therefore, the solutions of above differential equations are given by

$$
q_{r}(t)= \begin{cases}\frac{\left(D_{r}-d_{0}\right)}{d_{1}}\left(1-e^{-d_{1} t}\right), & 0 \leq t \leq t_{2} \\ -\frac{d_{0}}{d_{1}}\left[1-e^{-d_{1}(t-T)}\right], & t_{2} \leq t \leq T .\end{cases}
$$

Lemma 3.3. The distributor's time length of inventory $(T)$ is given by

$$
T=t_{2}+\frac{1}{d_{1}} \log \left\{1+\frac{\left(D_{r}-d_{0}\right)}{d_{0}}\left(1-e^{-d_{1} t_{2}}\right)\right\} .
$$


Proof. From the continuity conditions of $q_{r}(t)$ at $t=t_{2}$, we have

$$
\begin{aligned}
\frac{\left(D_{r}-d_{0}\right)}{d_{1}}\left(1-e^{-d_{1} t_{2}}\right) & =-\frac{d_{0}}{d_{1}}\left\{1-e^{-d_{1}\left(t_{2}-T\right)}\right\} \\
\Rightarrow\left(D_{r}-d_{0}\right)\left(1-e^{-d_{1} t_{2}}\right) & =-d_{0}\left\{1-e^{-d_{1}\left(t_{2}-T\right)}\right\} \\
\Rightarrow e^{-d_{1}\left(t_{2}-T\right)} & =1+\frac{\left(D_{r}-d_{0}\right)}{d_{0}}\left(1-e^{-d_{1} t_{2}}\right) \\
\Rightarrow T & =t_{2}+\frac{1}{d_{1}} \log \left\{1+\frac{\left(D_{r}-d_{0}\right)}{d_{0}}\left(1-e^{-d_{1} t_{2}}\right)\right\} .
\end{aligned}
$$

Holding cost of the distributor of the fresh unit is given by

$$
\begin{aligned}
\mathrm{HCR} & =h_{r}\left[\int_{0}^{t_{2}} q_{r}(t) \mathrm{d} t+\int_{t_{2}}^{T} q_{r}(t) \mathrm{d} t\right] \\
& =h_{r}\left[\frac{\left(D_{r}-d_{0}\right)}{d_{1}}\left\{t_{2}+\frac{1}{d_{1}}\left(e^{-d_{1} t_{2}}-1\right)\right\}-\frac{d_{0}}{d_{1}}\left\{\left(T-t_{2}\right)+\frac{1}{d_{1}}\left\{1-e^{-d_{1}\left(t_{2}-T\right)}\right\}\right\}\right] .
\end{aligned}
$$

Total procurement cost of the distributor is equal to

$$
\mathrm{PCR}=s_{m} D_{r} t_{2}
$$

Revenue of perfect quality items for the distributor is given below

$$
\begin{aligned}
\mathrm{SRR} & =s_{r}\left[\int_{0}^{t_{2}}\left(d_{0}+d_{1} q_{r}(t)\right) \mathrm{d} t+\int_{t_{2}}^{T}\left(d_{0}+d_{1} q_{r}(t)\right) \mathrm{d} t\right] \\
& =s_{r}\left[d_{0} T+\left(D_{r}-d_{0}\right)\left\{t_{2}+\frac{1}{d_{1}}\left(e^{-d_{1} t_{2}}-1\right)\right\}-d_{0}\left\{\left(T-t_{2}\right)+\frac{1}{d_{1}}\left\{1-e^{-d_{1}\left(t_{2}-T\right)}\right\}\right\}\right] \\
& =s_{r}\left[D_{r} t_{2}+\frac{\left(D_{r}-d_{0}\right)}{d_{1}}\left(e^{-d_{1} t_{2}}-1\right)-\frac{d_{0}}{d_{1}}\left\{1-e^{-d_{1}\left(t_{2}-T\right)}\right\}\right] .
\end{aligned}
$$

In this model, there are two credit periods, one is $M$ offered by the manufacturer and the another is offered by the distributor during $[0, N]$. Also, the distributor is charged for an interest by the manufacturer if the payment will not make within the offered credit period at a rate of $I_{p}$ per unit per year. Because of this relaxation period, the distributor can earn interest at a rate of $I_{e}$ per unit per year. But, the distributor wants to make payment after selling whole amounts i.e., at the end of his business cycle to earn more interest though this decision may take the risk of more interest payable amounts to the distributor.

Now, depending on the business time lengths of the distributor and the two types of credit periods, three different cases may arise. The model has been discussed in these three cases separately as follows:

Case 1: $N<M<t_{2}<T$.

Interest paid by the distributor $\left(\mathrm{IP}_{1}\right)$ is given by

$$
\begin{aligned}
\mathrm{IP}_{1} & =s_{m} I_{p} \int_{M}^{T} q_{r}(t) \mathrm{d} t \\
& =s_{m} I_{p}\left[\int_{M}^{t_{2}} q_{r}(t) \mathrm{d} t+\int_{t_{2}}^{T} q_{r}(t) \mathrm{d} t\right] \\
& =s_{m} I_{p}\left[\frac{\left(D_{r}-d_{0}\right)}{d_{1}}\left\{\left(t_{2}-M\right)+\frac{1}{d_{1}}\left(e^{-d_{1} t_{2}}-e^{-d_{1} M}\right)\right\}-\frac{d_{0}}{d_{1}}\left\{\left(T-t_{2}\right)+\frac{1}{d_{1}}\left\{1-e^{-d_{1}\left(t_{2}-T\right)}\right\}\right\}\right] .
\end{aligned}
$$


Interest earned by the distributor $\left(\mathrm{IE}_{1}\right)$ is given by

$$
\begin{aligned}
\mathrm{IE}_{1}= & s_{r} I_{e}\left[(T-N) \int_{0}^{N} D_{c}(t) \mathrm{d} t+\int_{N}^{t_{2}}(T-t) D_{c}(t) \mathrm{d} t+\int_{t_{2}}^{T}(T-t) D_{c}(t) \mathrm{d} t\right] \\
= & s_{r} I_{e}\left[(T-N) \int_{0}^{N}\left\{d_{0}+d_{1} q_{r}(t)\right\} \mathrm{d} t+\int_{N}^{t_{2}}(T-t)\left\{d_{0}+d_{1} q_{r}(t)\right\} \mathrm{d} t\right. \\
& \left.+\int_{t_{2}}^{T}(T-t)\left\{d_{0}+d_{1} q_{r}(t)\right\} \mathrm{d} t\right] \\
= & s_{r} I_{e}\left[(T-N)\left\{d_{0} N+\left(D_{r}-d_{0}\right)\left\{N+\frac{1}{d_{1}}\left(e^{-d_{1} N}-1\right)\right\}\right\}+\frac{D_{r}}{2}\left\{(T-N)^{2}-\left(T-t_{2}\right)^{2}\right\}\right. \\
+ & \frac{D_{r}-d_{0}}{d_{1}}\left\{\left(T-t_{2}\right) e^{-d_{1} t_{2}}-(T-N) e^{-d_{1} N}-\frac{1}{d_{1}}\left(e^{-d_{1} t_{2}}-e^{-d_{1} N}\right)\right\} \\
+ & \left.\frac{d_{0}}{d_{1}}\left(T-t_{2}\right) e^{-d_{1}\left(t_{2}-T\right)}+\frac{d_{0}}{d_{1}^{2}}\left\{1-e^{-d_{1}\left(t_{2}-T\right)}\right\}\right] .
\end{aligned}
$$

Therefore, in this case, the distributor's total profit $\left(\Pi_{r}^{(1)}\left(P, t_{1}\right)\right)$ is given by

$$
\Pi_{r}^{(1)}\left(P, t_{1}\right)=\mathrm{SRR}-\mathrm{PCR}-\mathrm{HCR}-\mathrm{IP}_{1}+\mathrm{IE}_{1}-A_{r} .
$$

So, in this case, the total profit of the integrated system $E\left[\operatorname{ITP}_{1}\left(P, t_{1}\right)\right]$ is written as

$$
E\left[\operatorname{ITP}_{1}\left(P, t_{1}\right)\right]=E\left[\Pi_{m}\left(P, t_{1}\right)\right]+\Pi_{r}^{(1)}\left(P, t_{1}\right) .
$$

Case 2: $N<t_{2}<M<T$.

Interest paid by the distributor $\left(\mathrm{IP}_{2}\right)$ is equal to

$$
\begin{aligned}
\mathrm{IP}_{2} & =s_{m} I_{p} \int_{M}^{T} q_{r}(t) \mathrm{d} t \\
& =s_{m} I_{p} \int_{M}^{T}-\frac{d_{0}}{d_{1}}\left[1-e^{-d_{1}(t-T)}\right] \mathrm{d} t \\
& =\frac{d_{0} s_{m} I_{p}}{d_{1}}\left[\frac{1}{d_{1}}\left\{e^{-d_{1}(M-T)}-1\right\}-(T-M)\right] .
\end{aligned}
$$

Interest earned by the distributor $\left(\mathrm{IE}_{2}\right)$ is given by

$$
\begin{aligned}
\mathrm{IE}_{2}= & s_{r} I_{e}\left[(T-N) \int_{0}^{N} D_{c}(t) \mathrm{d} t+\int_{N}^{t_{2}}(T-t) D_{c}(t) \mathrm{d} t+\int_{t_{2}}^{T}(T-t) D_{c}(t) \mathrm{d} t\right] \\
= & s_{r} I_{e}\left[(T-N) \int_{0}^{N}\left\{d_{0}+d_{1} q_{r}(t)\right\} \mathrm{d} t+\int_{N}^{t_{2}}(T-t)\left\{d_{0}+d_{1} q_{r}(t)\right\} \mathrm{d} t\right. \\
& \left.+\int_{t_{2}}^{T}(T-t)\left\{d_{0}+d_{1} q_{r}(t)\right\} \mathrm{d} t\right] \\
= & s_{r} I_{e}\left[(T-N)\left\{d_{0} N+\left(D_{r}-d_{0}\right)\left\{N+\frac{1}{d_{1}}\left(e^{-d_{1} N}-1\right)\right\}\right\}+\frac{D_{r}}{2}\left\{(T-N)^{2}-\left(T-t_{2}\right)^{2}\right\}\right.
\end{aligned}
$$




$$
\begin{aligned}
& +\frac{D_{r}-d_{0}}{d_{1}}\left\{\left(T-t_{2}\right) e^{-d_{1} t_{2}}-(T-N) e^{-d_{1} N}-\frac{1}{d_{1}}\left(e^{-d_{1} t_{2}}-e^{-d_{1} N}\right)\right\} \\
& \left.+\frac{d_{0}}{d_{1}}\left(T-t_{2}\right) e^{-d_{1}\left(t_{2}-T\right)}+\frac{d_{0}}{d_{1}^{2}}\left\{1-e^{-d_{1}\left(t_{2}-T\right)}\right\}\right] .
\end{aligned}
$$

Therefore, the distributor's total profit $\left(\Pi_{r}^{(2)}\left(P, t_{1}\right)\right)$ is given by

$$
\Pi_{r}^{(2)}\left(P, t_{1}\right)=\mathrm{SRR}-\mathrm{PCR}-\mathrm{HCR}-\mathrm{IP}_{2}+\mathrm{IE}_{2}-A_{r} .
$$

So, in this case, the total profit of the integrated system $E\left[\operatorname{ITP}_{2}\left(P, t_{1}\right)\right]$ is written as

$$
E\left[\operatorname{ITP}_{2}\left(P, t_{1}\right)\right]=E\left[\Pi_{m}\left(P, t_{1}\right)\right]+\Pi_{r}^{(2)}\left(P, t_{1}\right) .
$$

Case 3: $t_{2}<N<M<T$.

Interest paid by the distributor $\left(\mathrm{IP}_{3}\right)$ is given by

$$
\begin{aligned}
\mathrm{IP}_{3} & =s_{m} I_{p} \int_{M}^{T} q_{r}(t) \mathrm{d} t \\
& =s_{m} I_{p} \int_{M}^{T}-\frac{d_{0}}{d_{1}}\left[1-e^{-d_{1}(t-T)}\right] \mathrm{d} t \\
& =\frac{d_{0} s_{m} I_{p}}{d_{1}}\left[\frac{1}{d_{1}}\left\{e^{-d_{1}(M-T)}-1\right\}-(T-M)\right] .
\end{aligned}
$$

Interest earned by the distributor $\left(\mathrm{IE}_{3}\right)$ is equal to

$$
\begin{aligned}
\mathrm{IE}_{3}= & s_{r} I_{e}\left[(T-N)\left\{\int_{0}^{t_{2}} D_{c}(t) \mathrm{d} t+\int_{t_{2}}^{N} D_{c}(t) \mathrm{d} t\right\}+\int_{N}^{T}(T-t) D_{c}(t) \mathrm{d} t\right] \\
= & s_{r} I_{e}\left[(T-N)\left\{\int_{0}^{t_{2}}\left\{d_{0}+d_{1} q_{r}(t)\right\} \mathrm{d} t+\int_{t_{2}}^{N}\left\{d_{0}+d_{1} q_{r}(t)\right\} \mathrm{d} t\right\}+\int_{N}^{T}(T-t)\left\{d_{0}+d_{1} q_{r}(t)\right\} \mathrm{d} t\right] \\
= & s_{r} I_{e}\left[(T-N)\left\{d_{0} t_{2}+\left(D_{r}-d_{0}\right)\left\{t_{2}+\frac{1}{d_{1}}\left(e^{-d_{1} t_{2}}-1\right)\right\}+d_{0}\left\{\left(N-t_{2}\right)-\frac{1}{d_{1}}\left\{e^{-d_{1}(N-T)}-e^{-d_{1}\left(t_{2}-T\right)}\right\}\right\}\right\}\right. \\
& \left.+\frac{d_{0}}{d_{1}}(T-N) e^{-d_{1}(N-T)}+\frac{d_{0}}{d_{1}^{2}}\left\{1-e^{-d_{1}(N-T)}\right\}\right] .
\end{aligned}
$$

Therefore, the distributor's total profit is given by

$$
\Pi_{r}^{(3)}\left(P, t_{1}\right)=\mathrm{SRR}-\mathrm{PCR}-\mathrm{HCR}-\mathrm{IP}_{3}+\mathrm{IE}_{3}-A_{r} .
$$

So, in this case, the total profit of the integrated system $E\left[\operatorname{ITP}_{3}\left(P, t_{1}\right)\right]$ is written as

$$
E\left[\operatorname{ITP}_{3}\left(P, t_{1}\right)\right]=E\left[\Pi_{m}\left(P, t_{1}\right)\right]+\Pi_{r}^{(3)}\left(P, t_{1}\right) .
$$

\subsection{Model in integrating approach}

Here, the manufacturer and the distributor decide to share resources for mutually beneficial cooperation. Therefore, their expected integrated profit can be maximized by optimizing $P$ and $t_{1}$ for the three cases and is denoted by $E\left[\operatorname{ITP}\left(P, t_{1}\right)\right]$, is given by given by

$$
E\left[\operatorname{ITP}\left(P, t_{1}\right)\right]= \begin{cases}E\left[\operatorname{ITP}_{1}\left(P, t_{1}\right)\right]=E\left[\Pi_{m}\left(P, t_{1}\right)\right]+\Pi_{r}^{(1)}\left(P, t_{1}\right), & \text { if } N<M<t_{2}<T \\ E\left[\operatorname{ITP}_{2}\left(P, t_{1}\right)\right]=E\left[\Pi_{m}\left(P, t_{1}\right)\right]+\Pi_{r}^{(2)}\left(P, t_{1}\right), & \text { if } N<t_{2}<M<T \\ E\left[\operatorname{ITP}_{3}\left(P, t_{1}\right)\right]=E\left[\Pi_{m}\left(P, t_{1}\right)\right]+\Pi_{r}^{(3)}\left(P, t_{1}\right), & \text { if } t_{2}<N<M<T\end{cases}
$$




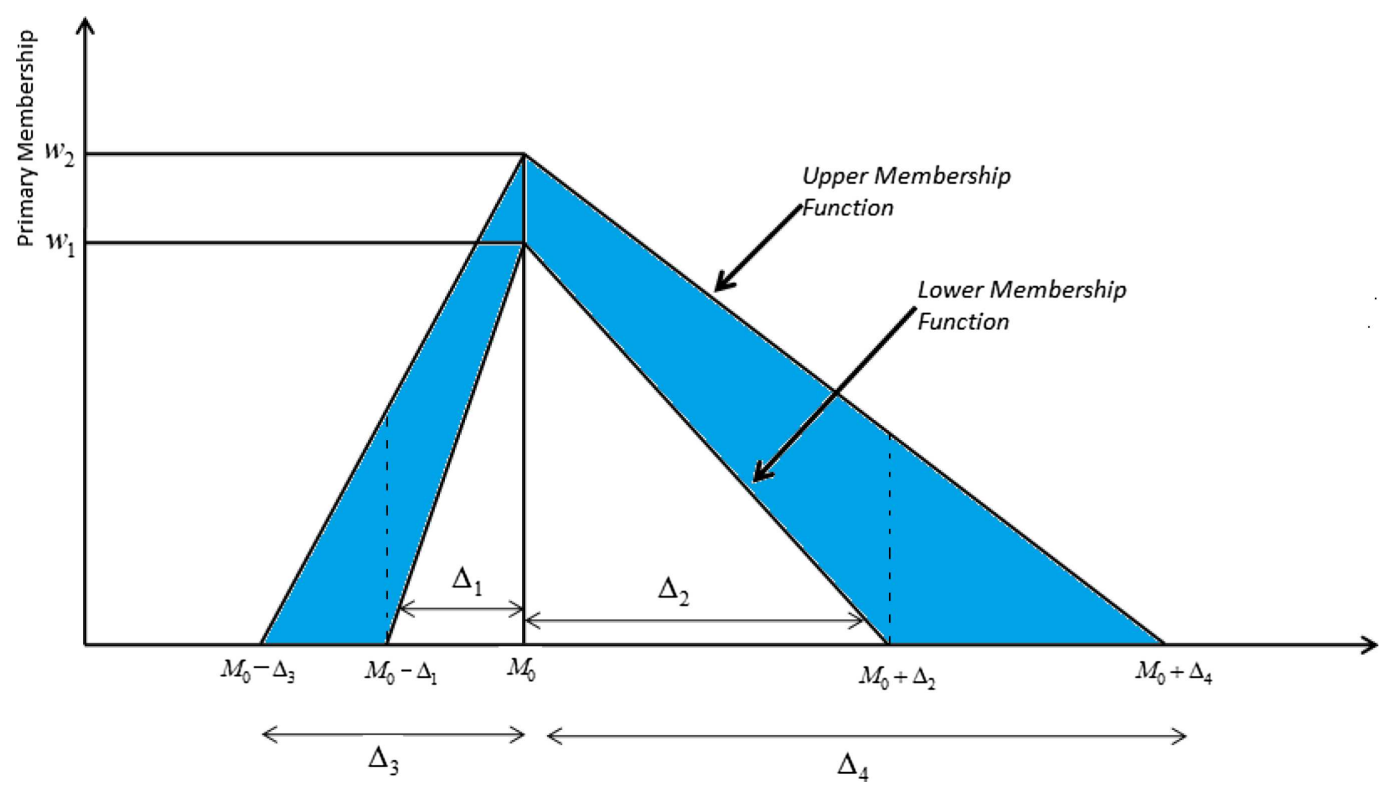

FIGURE 3. FOU of fuzzy credit period $\widetilde{\widetilde{M}}$.

\section{FUZZY MODEL}

In this paper, it is considered that the manufacturer provides a credit period to the distributor. Now, the question is that is the credit length always deterministic? Mainly, deciding credit period is own strategy of a manufacturer/supplier/retailer and also, there is no specific rules to assign length of a credit period. That means, it may be vague in nature. In that sense, the credit period $(M)$ is considered as generalized type-2 fuzzy set $\widetilde{\widetilde{M}}$. So, due to fuzziness of the credit period $(M)$, the optimum expected profit function also will be fuzzy in nature and it is denoted by $E\left[\operatorname{ITP}_{\left(P, t_{1}\right)}(\widetilde{\widetilde{M}})\right]$, where expression of $E\left[\operatorname{ITP}_{\left(P, t_{1}\right)}(\widetilde{\widetilde{M}})\right]$ for the three cases is same as the expression of $E\left[\operatorname{ITP}\left(P, t_{1}\right)\right]$ except $M$ is denoted by $\widetilde{\widetilde{M}}$. For simplicity, we have used the notation $\operatorname{ITP}_{\left(P, t_{1}\right)}(\widetilde{\widetilde{M}})$ irrespective of $E\left[\operatorname{ITP}_{\left(P, t_{1}\right)}(\widetilde{\widetilde{M}})\right]$ throughout the paper.

\section{1. $\widetilde{\widetilde{M}}$ : a generalized type-2 fuzzy set with triangular footprint of uncertainty and triangular secondary membership grade}

Here, we have considered the distributor's credit period $M$ as a generalized type-2 fuzzy set $(\widetilde{\widetilde{M}})$. Footprint of Uncertainty $($ FOU) and secondary membership function for the fuzzy set $\widetilde{\widetilde{M}}$ both are considered in triangular shape. Now, the type-2 fuzzy set $\widetilde{\widetilde{M}}$ is represented in the form of $\left[\left(M_{0}-\Delta_{1}, M_{0}, M_{0}+\Delta_{2}: w_{1}\right),\left(M_{0}-\Delta_{3}, M_{0}, M_{0}+\Delta_{4}: w_{2}\right)\right]$ (shown in Fig. 3) i.e., $\widetilde{\widetilde{M}}=\left[\widetilde{\widetilde{M}}^{L}, \widetilde{\widetilde{M}}^{U}\right]=$ $\left[\left(M_{0}-\Delta_{1}, M_{0}, M_{0}+\Delta_{2}: w_{1}\right),\left(M_{0}-\Delta_{3}, M_{0}, M_{0}+\Delta_{4}: w_{2}\right)\right]$, where $\widetilde{\widetilde{M}}^{L}$ and $\widetilde{\widetilde{M}}^{U}$ denote the lower and upper triangular type-2 fuzzy numbers; $w_{1}$ and $w_{2}$ are height of the lower and upper membership function $\left(0<w_{1}<w_{2} \leq 1\right) ; M_{0}-\Delta_{3}>0 ; M_{0}-\Delta_{3}<M_{0}-\Delta_{1} ; M_{0}+\Delta_{2}<M_{0}+\Delta_{4}$ and the associated values of the parameters $w_{1}, w_{2}, \Delta_{1}, \Delta_{2}, \Delta_{3}, \Delta_{4}$ are set by the decision makers. The lower membership function (LMF) of $\widetilde{\widetilde{M}}$ is defined as follows: 


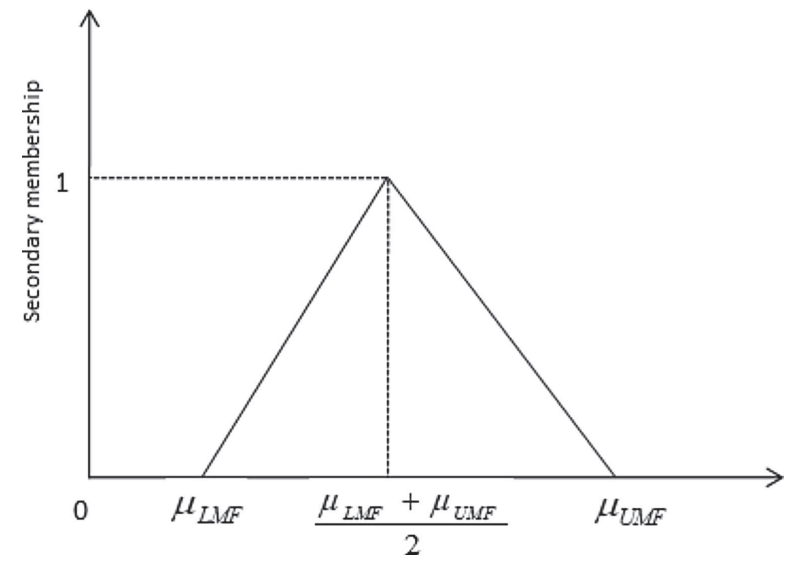

Figure 4. SMG at a point.

$$
\mu_{\mathrm{LMF}}(x)= \begin{cases}\frac{\left(x-M_{0}+\Delta_{1}\right) w_{1}}{\Delta_{1}} ; & \text { if } M_{0}-\Delta_{1} \leq x \leq M_{0} \\ \frac{\left(M_{0}+\Delta_{2}-x\right) w_{1}}{\Delta_{2}} ; & \text { if } M_{0} \leq x \leq M_{0}+\Delta_{2} \\ 0 ; & \text { otherwise }\end{cases}
$$

and the upper membership function of $\widetilde{\widetilde{M}}$ is defined as follows:

$$
\mu_{\mathrm{UMF}}(x)= \begin{cases}\frac{\left(x-M_{0}+\Delta_{3}\right) w_{2}}{\Delta_{3}} ; & \text { if } M_{0}-\Delta_{3} \leq x \leq M_{0} \\ \frac{\left(M_{0}+\Delta_{4}-x\right) w_{2}}{\Delta_{4}} ; & \text { if } M_{0} \leq x \leq M_{0}+\Delta_{4} \\ 0 ; & \text { otherwise. }\end{cases}
$$

Now, for any $x \in\left[M_{0}-\Delta_{3}, M_{0}+\Delta_{4}\right]$, the secondary membership function grade (SMG) is represented in the form $\left(t m_{1}, t m_{2}, t m_{3}\right)$ and defined as follows:

$$
t m_{1}=\mu_{\mathrm{LMF}}(x) ; \quad t m_{2}=\frac{\mu_{\mathrm{LMF}}(x)+\mu_{\mathrm{UMF}}(x)}{2} ; \quad t m_{3}=\mu_{\mathrm{UMF}}(x)
$$

where, the weights of $\mu_{\mathrm{LMF}}(x)$ and $\mu_{\mathrm{UMF}}(x)$ are considered as 1 . The associated figures are shown in Figure 4.

Lemma 4.1. The following properties must be satisfied by fuzzy credit period $\widetilde{\widetilde{M}}$ offered by the manufacturer:

(i) $M_{0}>\Delta_{3}$.

(ii) $\Delta_{3}>\Delta_{1}$.

(iii) $\Delta_{2}<\Delta_{4}$.

\subsection{Defuzzification of $\widetilde{\widetilde{M}}$}

Now, to get the defuzzified value of the credit period $\widetilde{\widetilde{M}}$, at first Type Reduced Set (TRS) of $\widetilde{\widetilde{M}}$ has to be find and then the centroid method has been used to obtain the crisp value like as defuzzification of type-1 fuzzy set. The necessary steps for defuzzification are described in below: 


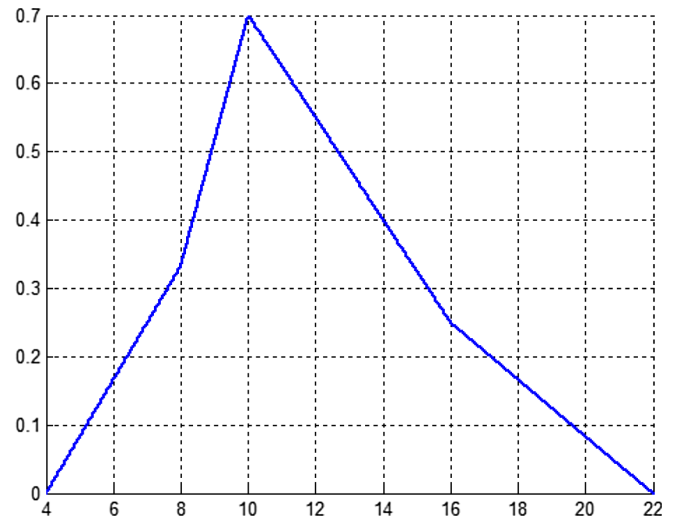

Figure 5. TRS of $\widetilde{\widetilde{M}}$.

\section{Step 1: Type Reduced Set (TRS) of $\widetilde{\widetilde{M}}$.}

At first, we denote TRS of the type-2 fuzzy credit period $(\widetilde{\widetilde{M}})$ in the domain $\left[M_{0}-\Delta_{3}, M_{0}+\Delta_{4}\right]$ as $\widetilde{M}=\left\{\left(x, \mu_{\widetilde{M}}(x)\right) \mid x \in\left[M_{0}-\Delta_{3}, M_{0}+\Delta_{4}\right]\right\}$, where the membership function $\mu_{\widetilde{M}}(x)$ of TRS at any point $x \in\left[M_{0}-\Delta_{3}, M_{0}+\Delta_{4}\right]$ is the centroid value of the corresponding secondary membership function of $x$. In this domain, the secondary membership function is a triangular fuzzy number in the form of $\left(t m_{1}, t m_{2}, t m_{3}\right)$. Therefore, the centroid value of the triangular fuzzy number in $x \in\left[M_{0}-\Delta_{3}, M_{0}+\Delta_{4}\right]$ is given by

$$
\begin{aligned}
\frac{1}{3}\left[t m_{1}+t m_{2}+t m_{3}\right] & =\frac{1}{3}\left[\mu_{\mathrm{LMF}}(x)+\frac{\mu_{\mathrm{LMF}}(x)+\mu_{\mathrm{UMF}}(x)}{2}+\mu_{\mathrm{UMF}}(x)\right] \\
& =\frac{\mu_{\mathrm{LMF}}(x)+\mu_{\mathrm{UMF}}(x)}{2} .
\end{aligned}
$$

Therefore, the expression for the membership function $\mu_{\widetilde{M}}(x)$ of the type reduced set is given by (the necessary steps for the calculations are shown in Appendix B)

$$
\mu_{\widetilde{M}}(x)= \begin{cases}\frac{\left(x-M_{0}+\Delta_{3}\right) w_{2}}{2 \Delta_{3}} ; & \text { if } M_{0}-\Delta_{3} \leq x \leq M_{0}-\Delta_{1} \\ \frac{1}{2}\left[\frac{\left(x-M_{0}\right)}{\Delta_{1} \Delta_{3}}\left(\Delta_{3} w_{1}+\Delta_{1} w_{2}\right)+\left(w_{1}+w_{2}\right)\right] ; & \text { if } M_{0}-\Delta_{1} \leq x \leq M_{0} \\ \frac{1}{2}\left[\frac{\left(M_{0}-x\right)}{\Delta_{2} \Delta_{4}}\left(\Delta_{4} w_{1}+\Delta_{2} w_{2}\right)+\left(w_{1}+w_{2}\right)\right] ; & \text { if } M_{0} \leq x \leq M_{0}+\Delta_{2} \\ \frac{\left(M_{0}+\Delta_{4}-x\right) w_{2}}{2 \Delta_{4}} ; & \text { if } M_{0}+\Delta_{2} \leq x \leq M_{0}+\Delta_{4} .\end{cases}
$$

The form of the membership function in above shows a pentagonal fuzzy number. The figure of the TRS of the type-2 fuzzy set with triangular footprint of uncertainty and triangular SMG has been shown in Figure 5 taking $M_{0}=10, \Delta_{1}=2, \Delta_{2}=4, \Delta_{3}=6$ and $\Delta_{4}=12$. 


\section{Step 2: Centroid value of $\widetilde{M}$.}

Here, we find out the centroid value $\left(M^{*}\right)$ of the fuzzy number $\widetilde{M}$ using centroid method as follows:

$$
M^{*}=\frac{\int_{-\infty}^{\infty} x \mu_{\widetilde{M}}(x) \mathrm{d} x}{\int_{-\infty}^{\infty} \mu_{\widetilde{M}}(x) \mathrm{d} x} .
$$

Hence the centroid value $\left(M^{*}\right)$ of $\widetilde{M}$ can be deduced as

$$
M^{*}=\frac{1}{3}\left[\begin{array}{c}
w_{1}\left\{\left(M_{0}+\Delta_{2}\right)-\left(M_{0}-\Delta_{1}\right)\right\}\left\{\left(M_{0}+\Delta_{2}\right)+M_{0}+\left(M_{0}-\Delta_{1}\right)\right\} \\
+w_{2}\left\{\left(M_{0}+\Delta_{4}\right)-\left(M_{0}-\Delta_{3}\right)\right\}\left\{\left(M_{0}+\Delta_{4}\right)+M_{0}+\left(M_{0}-\Delta_{3}\right)\right\} \\
w_{1}\left\{\left(M_{0}+\Delta_{2}\right)-\left(M_{0}-\Delta_{1}\right)\right\}+w_{2}\left\{\left(M_{0}+\Delta_{4}\right)-\left(M_{0}-\Delta_{3}\right)\right\}
\end{array}\right] .
$$

[The related calculations are described in Appendix C].

Theorem 4.2. The centroid value $\left(M^{*}\right)$ of the type-2 fuzzy credit period $\widetilde{\widetilde{M}}$ with triangular FOU and $S M G$ is given by

$$
M^{*}=\frac{1}{3}\left[\begin{array}{c}
w_{1}\left\{\left(M_{0}+\Delta_{2}\right)-\left(M_{0}-\Delta_{1}\right)\right\}\left\{\left(M_{0}+\Delta_{2}\right)+M_{0}+\left(M_{0}-\Delta_{1}\right)\right\} \\
\frac{+w_{2}\left\{\left(M_{0}+\Delta_{4}\right)-\left(M_{0}-\Delta_{3}\right)\right\}\left\{\left(M_{0}+\Delta_{4}\right)+M_{0}+\left(M_{0}-\Delta_{3}\right)\right\}}{w_{1}\left\{\left(M_{0}+\Delta_{2}\right)-\left(M_{0}-\Delta_{1}\right)\right\}+w_{2}\left\{\left(M_{0}+\Delta_{4}\right)-\left(M_{0}-\Delta_{3}\right)\right\}}
\end{array}\right] .
$$

Now, using Zadeh's extension principle in fuzzy set theory, we have constructed the FOU of the type-2 fuzzy profit function $\operatorname{ITP}_{\left(P, t_{1}\right)}(\widetilde{\widetilde{M}})$ where $\mathrm{UMF}$ and $\operatorname{LMF}$ of $\operatorname{ITP}_{\left(P, t_{1}\right)}(\widetilde{\widetilde{M}})$ can be written as follows:

$$
\mu_{\operatorname{UITP}_{\left(P, t_{1}\right)}(\widetilde{M})}(y)= \begin{cases}\frac{\left[\operatorname{ITP}_{\left(P, t_{1}\right)}^{-1}(y)-M_{0}+\Delta_{3}\right] w_{2}}{\Delta_{3}} ; & \text { if } y_{3} \leq y \leq y_{0} \\ \frac{\left[M_{0}+\Delta_{4}-\operatorname{ITP}_{\left(P, t_{1}\right)}^{-1}(y)\right] w_{2}}{\Delta_{4}} ; & \text { if } y_{0} \leq x \leq y_{4} \\ 0 ; & \text { otherwise }\end{cases}
$$

and

$$
\mu_{\operatorname{LITP}_{\left(P, t_{1}\right)}(\widetilde{M})}(y)= \begin{cases}\frac{\left[\operatorname{ITP}_{\left(P, t_{1}\right)}^{-1}(y)-M_{0}+\Delta_{1}\right] w_{1}}{\Delta_{1}} ; & \text { if } y_{1} \leq y \leq y_{0} \\ \frac{\left[M_{0}+\Delta_{2}-\operatorname{ITP}_{\left(P, t_{1}\right)}^{-1}(y)\right] w_{1}}{\Delta_{2}} ; & \text { if } y_{0} \leq x \leq y_{2} \\ 0 ; & \text { otherwise }\end{cases}
$$

where, $y_{0}=\operatorname{ITP}_{\left(P, t_{1}\right)}\left(M_{0}\right), y_{1}=\operatorname{ITP}_{\left(P, t_{1}\right)}\left(M_{0}-\Delta_{1}\right), y_{2}=\operatorname{ITP}_{\left(P, t_{1}\right)}\left(M_{0}+\Delta_{2}\right), y_{3}=\operatorname{ITP}_{\left(P, t_{1}\right)}\left(M_{0}-\Delta_{3}\right)$, $y_{4}=\operatorname{ITP}_{\left(P, t_{1}\right)}\left(M_{0}+\Delta_{4}\right)$.

For any $y \in\left[y_{3}, y_{4}\right]$, the corresponding secondary membership function is also a triangular fuzzy number whose apexes are of the form $\left(\mathrm{TM}_{1}, \mathrm{TM}_{2}, \mathrm{TM}_{3}\right)$ and defined as follows:

$$
\mathrm{TM}_{1}=\mu_{\operatorname{LITP}_{\left(P, t_{1}\right)}(\widetilde{M})}(y)
$$




$$
\begin{aligned}
\mathrm{TM}_{2} & =\frac{\mu_{\operatorname{LITP}_{\left(P, t_{1}\right)}(\widetilde{\widetilde{M}})}(y)+\mu_{\operatorname{UITP}_{\left(P, t_{1}\right)}(\widetilde{\widetilde{M}})}(y)}{2} \\
\mathrm{TM}_{3} & =\mu_{\operatorname{UITP}_{\left(P, t_{1}\right)}(\widetilde{\widetilde{M}})}(y) .
\end{aligned}
$$

Now, to find the defuzzified value of the type-2 fuzzy profit $\operatorname{ITP}_{\left(P, t_{1}\right)}(\widetilde{\widetilde{M}})$, we can obtain the TRS of $\operatorname{ITP}_{\left(P, t_{1}\right)}(\widetilde{\widetilde{M}})$ using the steps for Type Reduced Set of $\widetilde{\widetilde{M}}$ which is defined as

$$
\operatorname{ITP}_{\left(P, t_{1}\right)}(\widetilde{M})=\left\{\left(y, \mu_{\operatorname{ITP}_{T R S}(\widetilde{M})}(y)\right) \mid y \in\left[y_{3}, y_{4}\right]\right\} .
$$

Therefore, the membership function of the $\operatorname{TRS}, \operatorname{ITP}_{\left(P, t_{1}\right)}(\widetilde{M})$ can be obtained as follows:

$$
\mu_{\operatorname{ITP}_{T R S}(\widetilde{M})}(y)= \begin{cases}\frac{\left(\operatorname{ITP}_{\left(P, t_{1}\right)}^{-1}(y)-M_{0}+\Delta_{3}\right) w_{2}}{2 \Delta_{3}} ; & \text { if } y_{3} \leq y \leq y_{1} \\ \frac{1}{2}\left[\frac{\left(\operatorname{ITP}_{\left(P, t_{1}\right)}^{-1}(y)-M_{0}\right)}{\Delta_{1} \Delta_{3}}\left(\Delta_{3} w_{1}+\Delta_{1} w_{2}\right)+\left(w_{1}+w_{2}\right)\right] ; & \text { if } y_{1} \leq y \leq y_{0} \\ \frac{1}{2}\left[\frac{\left(M_{0}-\operatorname{ITP}_{\left(P, t_{1}\right.}^{-1}(y)\right)}{\Delta_{2} \Delta_{4}}\left(\Delta_{4} w_{1}+\Delta_{2} w_{2}\right)+\left(w_{1}+w_{2}\right)\right] ; & \text { if } y_{0} \leq y \leq y_{2} \\ \frac{\left(M_{0}+\Delta_{4}-\operatorname{ITP}_{\left(P, t_{1}\right)}^{-1}(y)\right) w_{2}}{2 \Delta_{4}} ; & \text { if } y_{2} \leq y \leq y_{4} .\end{cases}
$$

Now, according to Theorem 4.2 the centroid value $\left(\mathrm{CV}_{\text {ITP }}\right)$ of $\operatorname{ITP}_{\left(P, t_{1}\right)}(\widetilde{M})$ can be determined as follows:

$$
\begin{aligned}
\mathrm{CV}_{\text {ITP }} & =\frac{\int_{-\infty}^{\infty} y \mu_{\operatorname{ITP}_{T R S}(\widetilde{M})}(y) \mathrm{d} y}{\int_{-\infty}^{\infty} \mu_{\operatorname{ITP}_{T R S}(\widetilde{M})}(y) \mathrm{d} y} \\
& =\frac{1}{3}\left[\frac{w_{1}\left(y_{2}-y_{1}\right)\left(y_{2}+y_{0}+y_{1}\right)+w_{2}\left(y_{4}-y_{3}\right)\left(y_{4}+y_{0}+y_{3}\right)}{w_{1}\left(y_{2}-y_{1}\right)+w_{2}\left(y_{4}-y_{3}\right)}\right] .
\end{aligned}
$$

\subsection{Defuzzification algorithm for the type-2 fuzzy profit $\operatorname{ITP}_{\left(P, t_{1}\right)}(\widetilde{\widetilde{M}})$}

To get the defuzzified value of $\operatorname{ITP}_{\left(P, t_{1}\right)}(\widetilde{\widetilde{M}})$ with type-2 fuzzy credit period $\widetilde{\widetilde{M}}$, following steps are required.

Step 1. First obtain the expression for the crisp profit $E\left[\operatorname{ITP}\left(P, t_{1}\right)\right]$.

Step 2. Input the associated parametric values for the crisp model.

Step 3. Input the associated values for the lower and upper membership function of type-2 fuzzy credit period $\widetilde{\widetilde{M}}=\left[\left(M_{0}-\Delta_{1}, M_{0}, M_{0}+\Delta_{2}: w_{1}\right),\left(M_{0}-\Delta_{3}, M_{0}, M_{0}+\Delta_{4}: w_{2}\right)\right]$.

Step 4. Compute the values of $y_{0}, y_{1}, y_{2}, y_{3}, y_{4}$ where $y_{0}=\operatorname{ITP}_{\left(P, t_{1}\right)}\left(M_{0}\right), y_{1}=\operatorname{ITP}_{\left(P, t_{1}\right)}\left(M_{0}-\Delta_{1}\right), y_{2}=$ $\operatorname{ITP}_{\left(P, t_{1}\right)}\left(M_{0}+\Delta_{2}\right), y_{3}=\operatorname{ITP}_{\left(P, t_{1}\right)}\left(M_{0}-\Delta_{3}\right), y_{4}=\operatorname{ITP}_{\left(P, t_{1}\right)}\left(M_{0}+\Delta_{4}\right)$.

Step 5. Calculate the centroid value $\mathrm{CV}_{\text {ITP }}$ of $\operatorname{ITP}_{\left(P, t_{1}\right)}(\widetilde{\widetilde{M}})$ according to formula (4.2) and this is the required defuzzified value of the type-2 fuzzy profit $\operatorname{ITP}_{\left(P, t_{1}\right)}(\widetilde{\widetilde{M}})$.

\section{Numerical illustrations}

The following numerical examples have been considered to illustrate the above model. 


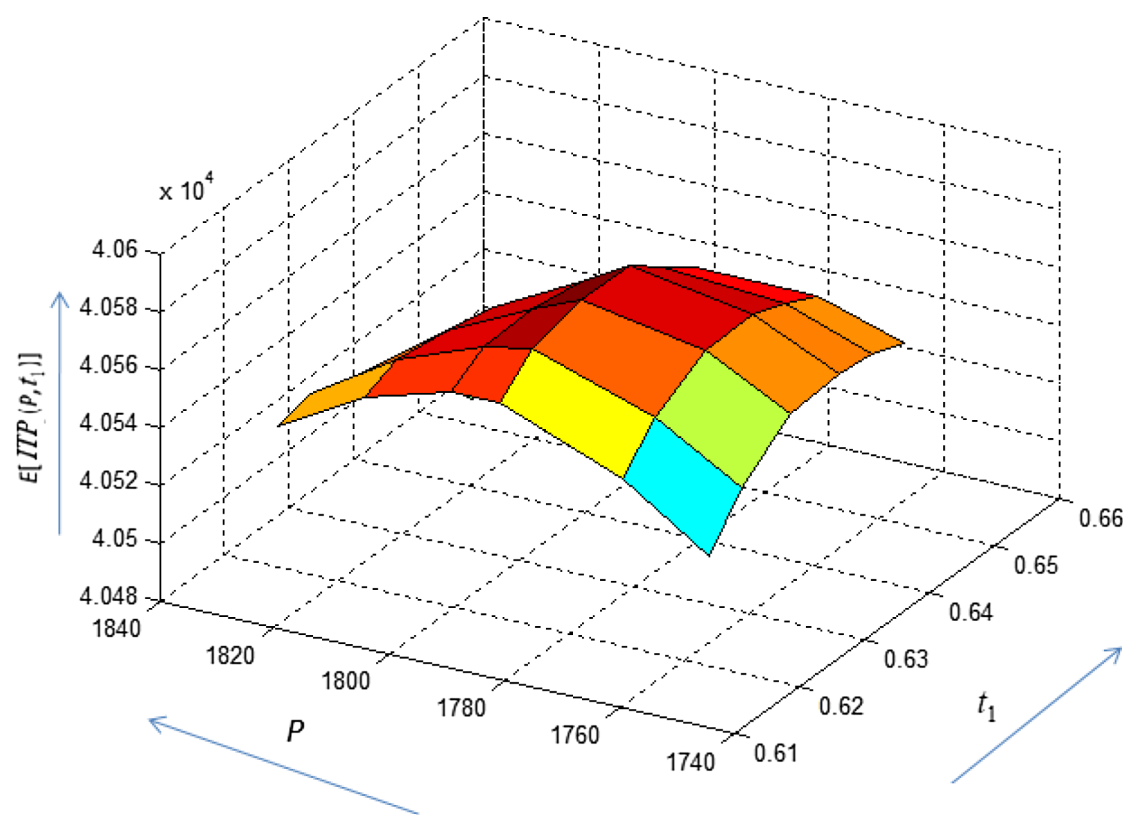

Figure 6. Concavity of the profit function $E\left[\operatorname{ITP}\left(P, t_{1}\right)\right]$.

\subsection{Results for crisp model}

Problem 1. The values of the associated parameters for the proposed model are considered in their appropriate units as follows: $c_{p_{1}}=\$ 7, s_{m}=\$ 50, s_{m}^{\prime}=c_{p}, s_{r}=\$ 80, c_{d}=\$ 1, s_{c}=\$ 2, r_{c m}=\$ 6, A_{m}=\$ 100, A_{r}=\$ 140$, $h_{m}=\$ 5, h_{m}^{\prime}=\$ 3.5, h_{r}=\$ 12, P_{0}=1200$ units, $D_{0}=500$ units, $d_{0}=350$ units, $\eta=0.8, \nu=1 / 6, \alpha=0.5$, $\lambda=1.85, \mu=0.02, b=1, d_{1}=0.01, \gamma=0.4, \delta=0.2, I_{c}=0.06, I_{p}=0.1, I_{e}=0.08$.

Solution: the obtained optimal results for the three cases have been shown in Table 2. Here, we have used Standard Lingo software to find out the optimal results. To justify the optimality of the results of the proposed model, we have presented a figure for Case 1 which is depicted in Figure 6 . The concavity nature of the figure supports that the integrated system's profit is optimum with respect to $P$ and $t_{1}$ for Case 1 . Similarly, it can be shown the concavity nature of the profit function for Cases 2 and 3 . In three cases, two credit periods are considered as follows: in Case $1-M=0.5$ year and $N=0.3$ year; in Case $2-M=1.05$ year and $N=0.3$ year; in Case $1-M=1.05$ year and $N=0.95$ year. Table 2 shows that Case 1 gives the most outcomes for the integrated system and the total produced items as well as the total ordered quantity for the distributor are higher than the other two cases. Table 2 also reflects that the optimal production-run time is less for Case 1 though production rate is higher comparatively other two cases. Now, the main difference between these three cases is the length of the credit period and their position. In Case 1, we see that the manufacturer offers a lower credit period than Cases 2 and 3 and the distributor's offered credit length is higher in Case 3 than other two cases. So, it is obvious that the demand rate of the distributor is lower in 1st case since the demand function of the distributor is linked with the credit period offered by the manufacturer. Again, it is considered that customers' demand is stock-dependent. Therefore, the integrated system reduces the production-run time and increases the total business period to adjust the demands in Case 1 with respect to other cases and gets best profit.

Now, in manufacturer's point of view, Case 1 gives minimum profit though in this case, he losses minimum opportunity for transferring more quantity. But, in this case, the manufacturer's holding cost is more due to less demand than the other two cases. Figure 7 depicts the comparative study of opportunity loss and holding cost of 

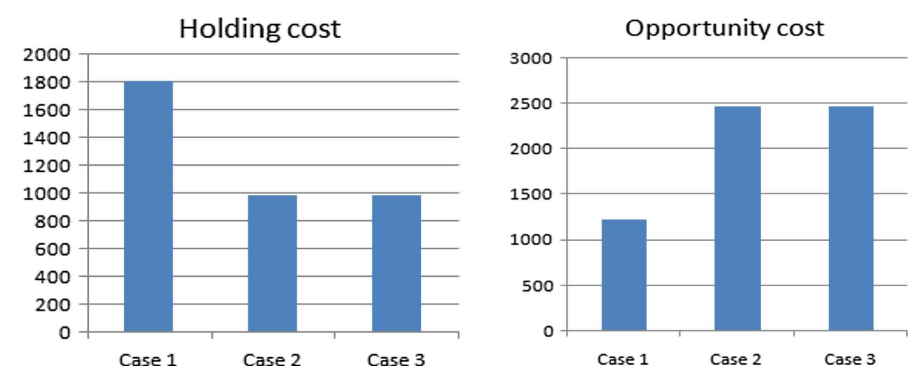

FiguRE 7. Comparison of holding cost and opportunity cost in three cases.

TABLE 2. Optimal results for crisp model.

\begin{tabular}{lllllllllll}
\hline \hline Cases & $c_{p}$ & $P$ & $t_{1}$ & $t_{2}$ & $T$ & $Q_{m}$ & $Q_{r}$ & $\Pi_{r}\left(P, t_{1}\right)$ & $E\left[\Pi_{m}\left(P, t_{1}\right)\right]$ & $E\left[\operatorname{ITP}\left(P, t_{1}\right)\right]$ \\
\hline$N<M<t_{2}<T$ & 18.72 & 1786.47 & 0.6277 & 1.2736 & 2.3239 & 1121.40 & 817.67 & 23248.54 & 17332.45 & 40580.99 \\
$N<t_{2}<M<T$ & 17.09 & 1704.58 & 0.6308 & 0.9269 & 2.2239 & 1075.38 & 783.46 & 21536.88 & 17525.78 & 39062.66 \\
$t_{2}<N<M<T$ & 17.09 & 1704.58 & 0.6308 & 0.9269 & 2.2239 & 1075.38 & 783.46 & 20622.50 & 17525.78 & 38148.29 \\
\hline
\end{tabular}

TABLE 3. Optimal results for fuzzy model where $\Delta_{1}=0.02, \Delta_{2}=0.04, \Delta_{3}=0.05, \Delta_{4}=0.08$.

\begin{tabular}{|c|c|c|c|c|c|c|c|c|c|c|c|}
\hline Cases & $c_{p}$ & $P$ & $t_{1}$ & $t_{2}$ & $T$ & $M^{*}$ & $Q_{m}$ & $Q_{r}$ & $\Pi_{r}\left(P, t_{1}\right)$ & $E\left[\Pi_{m}\left(P, t_{1}\right)\right]$ & $\mathrm{CV}_{\text {ITP }}$ \\
\hline$N<M<t_{2}<T$ & 18.69 & 1784.77 & 0.6277 & 1.2666 & 2.3218 & 0.5092 & 1120.45 & 816.96 & 23197.70 & 17342.08 & 40545.42 \\
\hline$N<t_{2}<M<T$ & 17.08 & 1704.47 & 0.6308 & 0.9225 & 2.2237 & 1.0592 & 1075.31 & 783.42 & 21535.10 & 17514.28 & 39047.93 \\
\hline
\end{tabular}

the manufacturer in three cases. Again, the distributor's point of view, Case 3 implies minimum profit. In Case 3 , it is noticed that the distributor offers a higher credit period and also distributor's business period collapses quickly due to high demand. As a result, the distributor losses the opportunity to get maximum interest from the selling amounts. Table 2 also reflects that the manufacturer's per unit production cost is more in Case 1, but it does not affect the system's profit. From this table, it is also observed that all the optimal values are the same except the distributor's and system's profit in Cases 2 and 3.

\subsection{Results for fuzzy model}

Problem 2. The problem is same as the Problem-1 except the credit period $(M)$ which is offered by the manufacturer. Here, the credit period is considered as type-2 fuzzy number $\widetilde{\widetilde{M}}$ which is considered in the form of $\left[\left(0.5-\Delta_{1}, 0.5,0.5+\Delta_{2}: 0.6\right),\left(0.5-\Delta_{3}, 0.5,0.5+\Delta_{4}: 1\right)\right]$.

Solution: Table 3 shows the optimal results for the three cases of the fuzzy model. From this table, it is seen that characteristic of optimal results for the three cases near about same as Table 2. But, irrespective of crisp model, the optimal results are not same for Cases 2 and 3 in fuzzy model. There is a slight difference in the optimal results for Cases 2 and 3 due to the fuzziness of the credit length. Table 3 shows that fuzziness of the credit period increase the credit length from its ground level.

\section{SENSitivity ANALYSiS AND MANAGERIAL INSIGHTS}

Now, to analyze the feasibility of the model, we have conducted a sensitivity analysis for Case 1 with respect to different parameters involving in the model. Also, some managerial insights have been drawn from this analysis. 


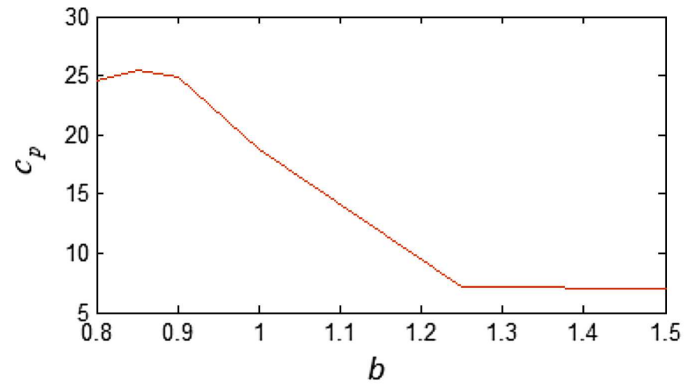

(a)

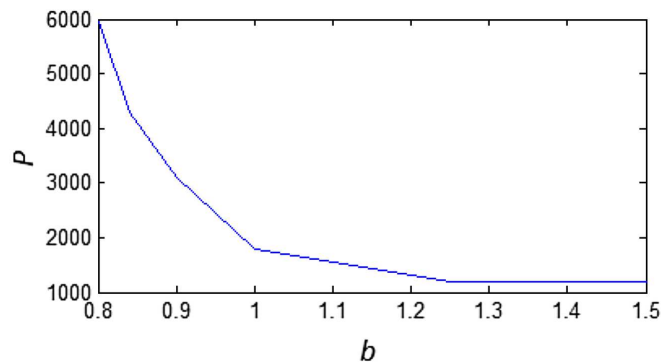

(b)

Figure 8. (a) b vs. $c_{p}$, (b) b vs. $P$.

TABLE 4. Analysis for different values of the parameter $b$.

\begin{tabular}{|c|c|c|c|c|c|c|c|c|c|c|}
\hline$b$ & $c_{p}$ & $P$ & $t_{1}$ & $t_{2}$ & $T$ & $Q_{m}$ & $Q_{r}$ & $\Pi_{r}\left(P, t_{1}\right)$ & $E\left[\Pi_{m}\left(P, t_{1}\right)\right]$ & $E\left[\operatorname{ITP}\left(P, t_{1}\right)\right]$ \\
\hline 0.80 & 24.50 & 5959.58 & 0.5103 & 3.7007 & 6.6869 & 3041.75 & 2375.95 & 61662.38 & 21553.24 & 83215.61 \\
\hline 0.85 & 25.49 & 4286.11 & 0.5393 & 2.7675 & 5.0194 & 2311.54 & 1776.82 & 47738.30 & 18249.97 & 65988.27 \\
\hline 0.90 & 24.84 & 3098.07 & 0.5688 & 2.0757 & 3.7752 & 1762.34 & 1330.67 & 36754.14 & 16826.43 & 53580.56 \\
\hline 1.00 & 18.72 & 1786.47 & 0.6277 & 1.2736 & 2.3239 & 1121.40 & 817.67 & 23248.54 & 17332.45 & 40580.99 \\
\hline 1.25 & 7.19 & 1206.09 & 0.6829 & 0.8977 & 1.6406 & 823.76 & 576.35 & 16617.26 & 20217.78 & 36835.04 \\
\hline 1.50 & 7.04 & 1201.73 & 0.6835 & 0.8948 & 1.6353 & 821.46 & 574.49 & 16565.16 & 20252.35 & 36817.51 \\
\hline
\end{tabular}

Tables 4-8 and Figures 8-16 show that optimal outcomes are fairly sensitive for different parameters which are discussed in below.

(i) Table 4 shows the changes of optimal values with the change of index parameter $b$ in the production cost function. From this table, it is noticed that production cost $c_{p}$ first increases and then decreases with the values of $b$ in $[0.8,0.9]$ and after that $c_{p}$ decreases gradually with increase of $b$ (cf. Fig. 8). Also, it is noticed that manufacturer production cost becomes too less according than normal production cost if $b>1$. But, the production rate gradually decreases with the increasing value of $b$ ( $c f$. Fig. 8) and it tends to normal production rate when $b>1$. Again, Figure 9 reflects the fact that the increase of $b$ implies the increase of production-run time $t_{1}$ but decrease of $t_{2}$ and $T$.

Now, assumption of production cost function reflects that a higher value of $b$ increases the production cost of an item for a certain value of $P$ and this fact does not go to the favor of the manufacturer. So, to sustain the balance of the system, the manufacturer should reduce the production rate which may be fruitful for the manufacturer. But, from Table 4, it is observed that total ordered size as well as the distributor's and the integrated system's profit decreases gradually with $b$. It is also observed that the manufacturer's profit follows convex nature with the increasing value of $b$. Hence, it can be said that the manufacturer must focus on how the production rate affects the cost of production of an item for different $b$ so that the integrated system will be profitable.

(ii) Table 5 shows the results for different values of normal rate $P_{0}$ of the manufacturer. From this table, it is seen that if the normal production rate increases then the system's optimal production rate $P$ also increases, however, the manufacturer's unit production cost decreases and ordered lot size of the distributor, total produced items also increase. Also, the integrated system's profit increases with the increase of $P_{0}$ as well as the manufacturer's and the distributor's profit increase. Again, it is also noticed from the table that the production-run time $\left(t_{1}\right)$ as well as total business cycle length $(T)$ increase with the increase in $P_{0}$. 
TABle 5. Analysis for $P_{0}$.

\begin{tabular}{|c|c|c|c|c|c|c|c|c|c|c|}
\hline$P_{0}$ & $c_{p}$ & $P$ & $t_{1}$ & $t_{2}$ & $T$ & $Q_{m}$ & $Q_{r}$ & $\Pi_{r}\left(P, t_{1}\right)$ & $E\left[\Pi_{m}\left(P, t_{1}\right)\right]$ & $E\left[\operatorname{ITP}\left(P, t_{1}\right)\right.$ \\
\hline 900 & 22.32 & 1666.47 & 0.6203 & 1.1892 & 2.1706 & 1033.83 & 763.48 & 21776.92 & 13371.80 & 35148.72 \\
\hline 1000 & 21.12 & 1706.40 & 0.6228 & 1.2174 & 2.2218 & 1062.91 & 781.58 & 22269.57 & 14644.89 & 36914.89 \\
\hline 1100 & 19.92 & 1746.40 & 0.6253 & 1.2455 & 2.2729 & 1092.10 & 799.64 & 22760.11 & 15965.09 & 38725.20 \\
\hline 1200 & 18.72 & 1786.47 & 0.6277 & 1.2736 & 2.3239 & 1121.40 & 817.67 & 23248.54 & 17332.45 & 40580.99 \\
\hline 1300 & 17.53 & 1826.61 & 0.6300 & 1.3016 & 2.3747 & 1150.82 & 835.65 & 23734.85 & 18747.02 & 42481.87 \\
\hline
\end{tabular}

TABLE 6. Sensitivity analysis for different cost parameters and $M$.

\begin{tabular}{|c|c|c|c|c|c|c|c|c|c|c|c|}
\hline Parameters & $\begin{array}{l}\text { Change } \\
(\text { in } \%)\end{array}$ & $c_{p}$ & $P$ & $t_{1}$ & $t_{2}$ & $T$ & $Q_{m}$ & $Q_{r}$ & $\Pi_{r}\left(P, t_{1}\right)$ & $E\left[\Pi_{m}\left(P, t_{1}\right)\right]$ & $E\left[\operatorname{ITP}\left(P, t_{1}\right)\right]$ \\
\hline \multirow{4}{*}{$c_{p_{1}}$} & $-50 \%$ & $-11.16 \%$ & $+3.94 \%$ & $+0.64 \%$ & $+3.84 \%$ & $+3.83 \%$ & $+4.60 \%$ & $+3.85 \%$ & $+3.65 \%$ & $+14.46 \%$ & $+8.27 \%$ \\
\hline & $-25 \%$ & $-5.56 \%$ & $+1.97 \%$ & $+0.32 \%$ & $+1.92 \%$ & $+1.91 \%$ & +2.29 & $+1.92 \%$ & $+1.83 \%$ & $+7.13 \%$ & $+4.09 \%$ \\
\hline & $+25 \%$ & $+5.61 \%$ & $-1.96 \%$ & $-0.33 \%$ & $-1.93 \%$ & $-1.92 \%$ & $-2.29 \%$ & $-1.93 \%$ & $-1.84 \%$ & $-6.92 \%$ & $-4.01 \%$ \\
\hline & $+50 \%$ & $+11.22 \%$ & $-3.92 \%$ & $-0.67 \%$ & $-3.86 \%$ & $-3.84 \%$ & $-4.57 \%$ & $-3.86 \%$ & $-3.68 \%$ & $-13.63 \%$ & $-7.93 \%$ \\
\hline \multirow{3}{*}{$h_{m}$} & $-25 \%$ & $+3.04 \%$ & $+1.58 \%$ & $-0.27 \%$ & $+1.41 \%$ & $+1.40 \%$ & $+1.31 \%$ & $+1.41 \%$ & $+1.34 \%$ & $+0.72 \%$ & $+1.08 \%$ \\
\hline & $+25 \%$ & $-2.88 \%$ & $-1.53 \%$ & $+0.27 \%$ & $-1.37 \%$ & $-1.36 \%$ & $-1.26 \%$ & $-1.37 \%$ & $-1.30 \%$ & $-0.68 \%$ & $-1.04 \%$ \\
\hline & $+50 \%$ & $-5.72 \%$ & $-3.00 \%$ & $+0.53 \%$ & $-2.69 \%$ & $-2.67 \%$ & $-2.48 \%$ & $-2.69 \%$ & $-2.56 \%$ & $-1.33 \%$ & $-2.03 \%$ \\
\hline \multirow{3}{*}{$h_{r}$} & $-50 \%$ & $+13.51 \%$ & $+7.08 \%$ & $-0.72 \%$ & $+6.43 \%$ & $+6.39 \%$ & $+6.31 \%$ & $+6.43 \%$ & $+18.65 \%$ & $-9.20 \%$ & $+6.76 \%$ \\
\hline & $-25 \%$ & $+6.57 \%$ & $+3.43 \%$ & $-0.51 \%$ & $+3.12 \%$ & $+3.10 \%$ & $+3.06 \%$ & $+3.12 \%$ & $+8.86 \%$ & $-4.22 \%$ & $+3.27 \%$ \\
\hline & $+25 \%$ & $-6.14 \%$ & $-3.23 \%$ & $+0.35 \%$ & $-2.95 \%$ & $-2.93 \%$ & $-2.89 \%$ & $-2.95 \%$ & $-8.03 \%$ & $+3.56 \%$ & $-3.08 \%$ \\
\hline \multirow{3}{*}{$M$} & $-25 \%$ & $+2.67 \%$ & $+1.39 \%$ & $-0.14 \%$ & $+7.79 \%$ & $+1.30 \%$ & $+1.24 \%$ & $+1.26 \%$ & $+3.29 \%$ & $-0.95 \%$ & $+1.48 \%$ \\
\hline & $+25 \%$ & $-2.46 \%$ & $-1.31 \%$ & $+0.13 \%$ & $-7.18 \%$ & $-1.22 \%$ & $-1.17 \%$ & $-1.19 \%$ & $-2.75 \%$ & $+0.71 \%$ & $-1.27 \%$ \\
\hline & $+50 \%$ & $-4.81 \%$ & $-2.53 \%$ & $+0.27 \%$ & $-13.80 \%$ & $-2.37 \%$ & $-2.27 \%$ & $-2.31 \%$ & $-4.93 \%$ & $+1.22 \%$ & $-2.30 \%$ \\
\hline
\end{tabular}

TABLE 7. Sensitivity analysis for different parameters.

\begin{tabular}{|c|c|c|c|c|c|c|c|c|c|c|c|}
\hline Parameters & $\begin{array}{l}\text { Change } \\
\text { (in \%) }\end{array}$ & $c_{p}$ & $P$ & $t_{1}$ & $t_{2}$ & $T$ & $Q_{m}$ & $Q_{r}$ & $\Pi_{r}\left(P, t_{1}\right)$ & $E\left[\Pi_{m}\left(P, t_{1}\right)\right]$ & $E\left[\operatorname{ITP}\left(P, t_{1}\right)\right]$ \\
\hline \multirow{4}{*}{$\eta$} & $-50 \%$ & $-6.89 \%$ & $-3.62 \%$ & $+42.06 \%$ & $+36.76 \%$ & $+36.50 \%$ & $+37.24 \%$ & $+36.76 \%$ & $+34.35 \%$ & $+41.63 \%$ & $+37.46 \%$ \\
\hline & $-25 \%$ & $-2.62 \%$ & $-1.39 \%$ & $+15.64 \%$ & $+14.01 \%$ & $+13.90 \%$ & $+14.05 \%$ & $+14.01 \%$ & $+13.24 \%$ & $+15.57 \%$ & $+17.24 \%$ \\
\hline & $+25 \%$ & $+1.87 \%$ & $+0.98 \%$ & $-10.66 \%$ & $-9.77 \%$ & $-9.72 \%$ & $-9.78 \%$ & $-9.77 \%$ & $-9.34 \%$ & $-10.64 \%$ & $-9.89 \%$ \\
\hline & $+50 \%$ & $+3.31 \%$ & $+1.71 \%$ & $-18.51 \%$ & $-17.09 \%$ & $-17.01 \%$ & $-17.83 \%$ & $-17.08 \%$ & $-16.40 \%$ & $-18.49 \%$ & $-17.30 \%$ \\
\hline \multirow{4}{*}{$\delta$} & $-50 \%$ & $+1.28 \%$ & $+0.66 \%$ & $-5.43 \%$ & $-5.01 \%$ & $-4.98 \%$ & $-4.56 \%$ & $-4.79 \%$ & $-4.78 \%$ & $-4.70 \%$ & $-4.75 \%$ \\
\hline & $-25 \%$ & $0.69 \%$ & $+0.34 \%$ & $-2.94 \%$ & $-2.61 \%$ & $-2.59 \%$ & $-2.36 \%$ & $-2.38 \%$ & $-2.48 \%$ & $-2.44 \%$ & $-2.46 \%$ \\
\hline & $+25 \%$ & $-0.69 \%$ & $-0.37 \%$ & $+2.67 \%$ & $+2.83 \%$ & $+2.81 \%$ & $+2.55 \%$ & $+3.06 \%$ & $+2.69 \%$ & $+2.63 \%$ & $+2.66 \%$ \\
\hline & $+50 \%$ & $-1.50 \%$ & $-0.78 \%$ & $+5.86 \%$ & $+5.91 \%$ & $5.88 \%$ & $+5.30 \%$ & $+6.15 \%$ & $+5.61 \%$ & $+5.47 \%$ & $+5.55 \%$ \\
\hline \multirow{4}{*}{$\nu$} & $-50 \%$ & $-1.92 \%$ & $-1.02 \%$ & $+36.21 \%$ & $+35.16 \%$ & $+34.92 \%$ & $+34.82 \%$ & $+35.17 \%$ & $+32.89 \%$ & $+33.45 \%$ & $+33.13 \%$ \\
\hline & $-25 \%$ & $-0.69 \%$ & $-0.38 \%$ & $+16.70 \%$ & $+16.41 \%$ & $+16.31 \%$ & $+16.26 \%$ & $+16.41 \%$ & $+15.50 \%$ & $+15.51 \%$ & $+15.50 \%$ \\
\hline & $+25 \%$ & $+0.27 \%$ & $+0.13 \%$ & $-14.29 \%$ & $-14.30 \%$ & $-14.23 \%$ & $-14.17 \%$ & $-14.30 \%$ & $-13.71 \%$ & $-13.40 \%$ & $-13.58 \%$ \\
\hline & $+50 \%$ & $+0.05 \%$ & $+0.02 \%$ & $-26.53 \%$ & $-26.72 \%$ & $-26.61 \%$ & $-26.51 \%$ & $-26.72 \%$ & $-25.79 \%$ & $-25.01 \%$ & $-25.45 \%$ \\
\hline \multirow{4}{*}{$\mu$} & $-50 \%$ & $+24.52 \%$ & $+58.48 \%$ & $-7.38 \%$ & $+50.81 \%$ & $+50.41 \%$ & $+46.81 \%$ & $+50.81 \%$ & $+47.15 \%$ & $+4.04 \%$ & $+28.74 \%$ \\
\hline & $-25 \%$ & $+13.78 \%$ & $+20.56 \%$ & $-3.25 \%$ & $+18.13 \%$ & $+18.02 \%$ & $+16.65 \%$ & $+18.13 \%$ & $+17.10 \%$ & $-0.73 \%$ & $+9.49 \%$ \\
\hline & $+25 \%$ & $-15.12 \%$ & $-12.91 \%$ & $+2.72 \%$ & $-11.58 \%$ & $-11.52 \%$ & $-10.54 \%$ & $-11.58 \%$ & $-11.09 \%$ & $+3.01 \%$ & $-5.07 \%$ \\
\hline & $+50 \%$ & $-30.98 \%$ & $-21.78 \%$ & $+5.07 \%$ & $-19.64 \%$ & $-19.55 \%$ & $-17.80 \%$ & $-19.63 \%$ & $-18.88 \%$ & $+7.17 \%$ & $-7.75 \%$ \\
\hline \multirow{4}{*}{$\gamma$} & $-50 \%$ & $+8.23 \%$ & $+4.29 \%$ & $+2.23 \%$ & $+4.43 \%$ & $+4.51 \%$ & $+6.62 \%$ & $+4.54 \%$ & $+4.31 \%$ & $+1.61 \%$ & $+3.15 \%$ \\
\hline & $-25 \%$ & $+3.90 \%$ & $+2.02 \%$ & $+1.04 \%$ & $+2.15 \%$ & $+2.14 \%$ & $+3.08 \%$ & $+2.15 \%$ & $+2.05 \%$ & $+0.77 \%$ & $+1.50 \%$ \\
\hline & $+25 \%$ & $-3.47 \%$ & $-1.84 \%$ & $-0.91 \%$ & $-1.97 \%$ & $-1.96 \%$ & $-2.73 \%$ & $-1.97 \%$ & $-1.87 \%$ & $-0.71 \%$ & $-1.38 \%$ \\
\hline & $+50 \%$ & $-6.68 \%$ & $-3.52 \%$ & $-1.70 \%$ & $-3.78 \%$ & $-3.76 \%$ & $-5.17 \%$ & $-3.78 \%$ & $-3.60 \%$ & $-1.37 \%$ & $-2.65 \%$ \\
\hline
\end{tabular}


TABLE 8. Analysis for fuzzy model.

\begin{tabular}{|c|c|c|c|c|c|c|c|c|c|c|c|c|}
\hline & & $c_{p}$ & $P$ & $t_{1}$ & $t_{2}$ & $T$ & $M^{*}$ & $Q_{m}$ & $Q_{r}$ & $\Pi_{r}\left(P, t_{1}\right)$ & $E\left[\Pi_{m}\left(P, t_{1}\right)\right]$ & $\mathrm{CV}_{\text {ITP }}$ \\
\hline \multirow{4}{*}{$\Delta_{1}=0.02$} & $\Delta_{2}$ & & & & & & & & & & & \\
\hline & $\overline{0.02}$ & 18.6988 & 1784.94 & 0.6277 & 1.2672 & 2.3220 & 0.5084 & 1120.54 & 817.57 & 23202.53 & 17341.12 & 40549.40 \\
\hline & 0.03 & 18.6976 & 1784.88 & 0.6277 & 1.2670 & 2.3219 & 0.5087 & 1120.51 & 817.01 & 23200.82 & 17341.33 & 40547.86 \\
\hline & 0.04 & 18.6955 & 1784.77 & 0.6277 & 1.2666 & 2.3218 & 0.5092 & 1120.45 & 816.96 & 23197.70 & 17342.08 & 40545.42 \\
\hline \multirow{3}{*}{$\Delta_{1}=0.03$} & 0.02 & 18.7024 & 1785.12 & 0.6277 & 1.2679 & 2.3222 & 0.5075 & 1120.64 & 817.10 & 23207.62 & 17340.02 & 40553.57 \\
\hline & 0.03 & 18.7011 & 1785.05 & 0.6277 & 1.2677 & 2.3222 & 0.5078 & 1120.60 & 817.07 & 23205.45 & 17340.45 & 40551.93 \\
\hline & 0.04 & 18.6990 & 1784.95 & 0.6277 & 1.2673 & 2.3220 & 0.5083 & 1120.55 & 817.03 & 23202.97 & 17341.12 & 40549.44 \\
\hline \multirow{4}{*}{$\Delta_{3}=0.05$} & $\Delta_{4}$ & & & & & & & & & & & \\
\hline & $\overline{0.07}$ & 18.70 & 1785.26 & 0.6277 & 1.2686 & 2.3224 & 0.5066 & 1120.72 & 817.16 & 23212.28 & 17339.35 & 40556.04 \\
\hline & 0.08 & 18.69 & 1784.77 & 0.6277 & 1.2666 & 2.3218 & 0.5092 & 1120.45 & 816.96 & 23197.70 & 17342.08 & 40545.42 \\
\hline & 0.09 & 18.68 & 1784.27 & 0.6278 & 1.2646 & 2.3212 & 0.5119 & 1120.17 & 816.75 & 23183.21 & 17345.21 & 40534.61 \\
\hline \multirow{3}{*}{$\Delta_{3}=0.06$} & 0.07 & 18.41 & 1785.77 & 0.6277 & 1.2706 & 2.3230 & 0.5040 & 1121.01 & 817.38 & 23226.93 & 17336.23 & 40568.42 \\
\hline & 0.08 & 18.70 & 1785.29 & 0.6277 & 1.2686 & 2.3224 & 0.5066 & 1120.74 & 817.17 & 23212.57 & 17339.05 & 40557.78 \\
\hline & 0.09 & 18.69 & 1784.79 & 0.6277 & 1.2666 & 2.3218 & 0.5093 & 1120.46 & 816.96 & 23197.77 & 17341.91 & 40546.98 \\
\hline
\end{tabular}

So, it can be said that if the primary production capability of a manufacturing system is high, it is quite effective for the system. However, in general, it is not always possible for a manufacturing company to increase production rate arbitrarily. Each manufacturing process has a certain range of production rate according to the efficiency of the machinery system and the workers. Hence increasing value of $P_{0}$ may cause of bad system's functionality. In this regard, a suitable normal production rate $\left(P_{0}\right)$ is really sensible for the system.

(iii) The production-run time $t_{1}$ increases slowly with increase of $M$ whereas $t_{2}$ and $T$ decreases with increase in $M$ ( $c f$. Fig. 10). Also, higher credit length reduces production rate as well as the total quantity that will be delivered by the manufacturer and hence total business cycle length also decreases (cf. Tab. 6). Figure 11 shows that the distributor's and the system's optimal profit decreases with increase in $M$, but the manufacturer's optimal profit increases. This scenario quite opposite regarding natural fact since higher credit length means more opportunity loss for a manufacturer. Now, a higher value of $M$ increases the distributor's demand rate and hence, the total business cycle decreases due to stock-dependent demand of customers. Again, from Table 6, it is seen that the production cost of item is also reduced which indicates a good effect for the manufacturer.

Thus, it can be noticed that the decision of a smaller business cycle length is beneficial for the manufacturer even though the credit period given by the manufacturer is longer. But, it reduces the entire system's profit due to the low sales volume. Again, in developing countries, manufacturers do not want to take the burden of opportunity loss. Now, since providing credit period is totally own choice of the manufacturer, so the manufacturer should look at the offered credit length to maintain the entire system's motive.

(iv) We have studied the changes in optimal values (in \%) with respect to different cost parameters which is shown in Table 6 . With increase in normal production cost of an item, the optimal production cost increases and the production rate as well as production run-time decreases and obviously, this indicates smaller lot-size for the distributor. Thus, the higher production cost decreases the system's profit.

(v) Higher holding cost per unit item for the manufacturer indicates a lower production rate and hence, lower production cost ( $c f$. Tab. 6). Since higher production rate stores more items per unit time, therefore the manufacturer's total holding cost increases. So, in this situation, the manufacturer has to reduce the production rate to reduce the holding cost. Also, it can be said that the manufacturer does not want to continue his business period for a long time. Thus, this scenario causes smaller lot-size for the distributor and smaller lot-size minimizes total profit.

(vi) Again, from Table 6, it is observed that a higher holding cost per unit item for the distributor implies lower lot-size. Now, due to higher holding cost, a distributor obviously does not stock more items in one 


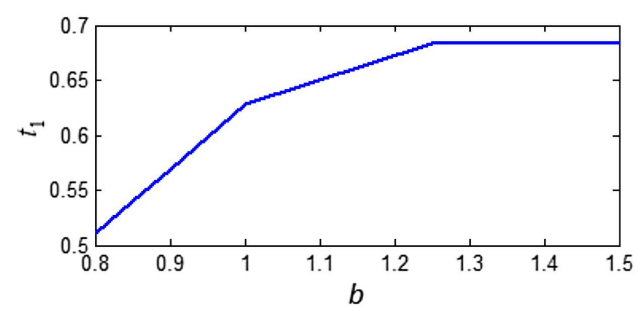

(a)

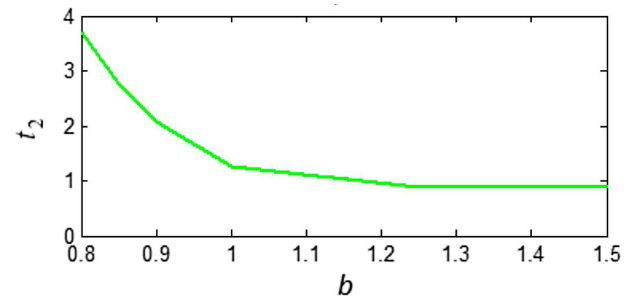

(b)

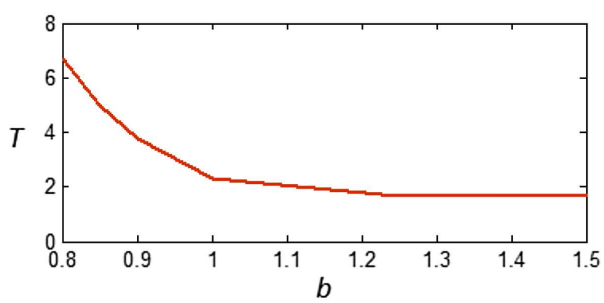

(c)

Figure 9. Change of $t_{1}, t_{2}, T$ w.r.t $b$.

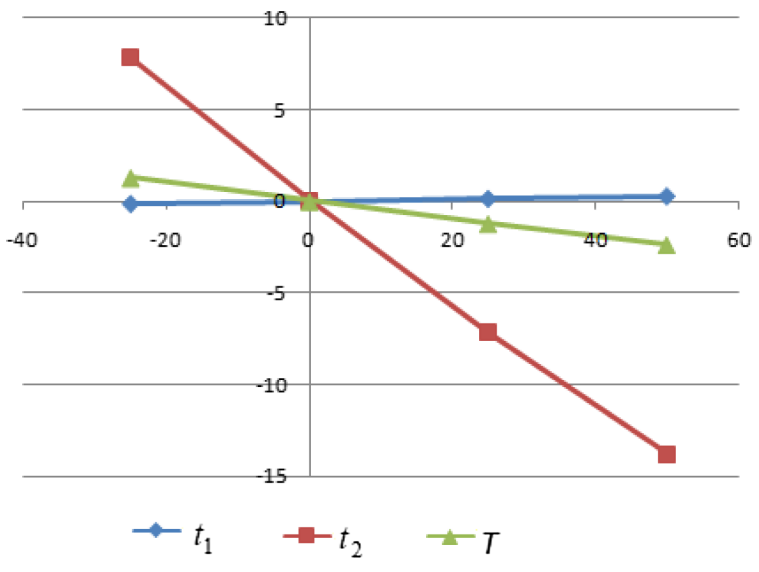

Figure 10 . Change of $t_{1}, t_{2}, T$ in (\%) w.r.t $M$.

cycle. So, the manufacturer reduces the production rate and this fact reduces the unit production cost which is quite good for the manufacturer. Hence, the system's profit decreases due to the higher holding cost for the distributor. So, it can be concluded that smaller business cycle length is helpful for both the distributor and the manufacturer whenever per unit holding cost is more for both.

(vii) Figure 12 presents the changes in the parameter $T$ and optimal profits with respect to the distributor's offered credit period $N$. This picture shows that the total business period and the manufacturer's profit remain same with respect to $N$. Since this credit length $(N)$ is only the distributor's choice to create a bond with his customers and it has no such effect on the system, it induces only the distributor's profit function negatively. Hence, automatically, the system profit decreases with the increase of $N$.

(viii) From Table 7, it is seen that the higher value of the normal rate of imperfect production $(\eta)$ increases the optimal production rate. Now, the higher rate of imperfect production means more defective (imperfect) items. Thus, the manufacturer must increase the production rate to maintain the demand for the system. 


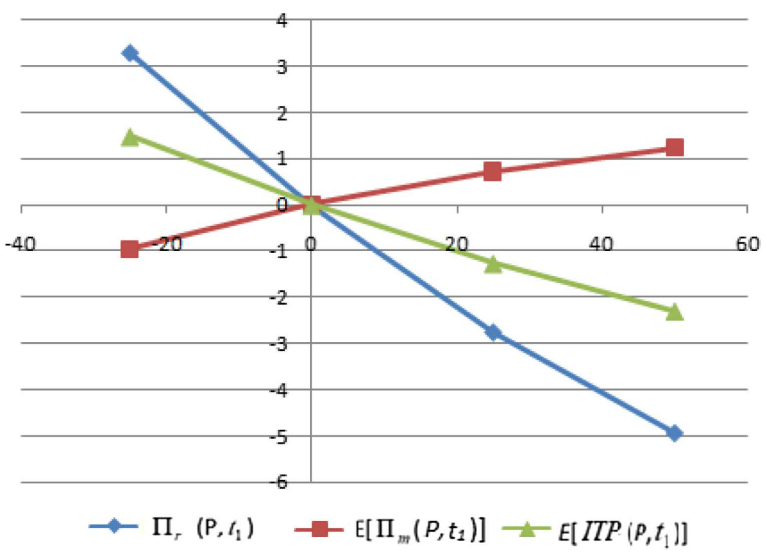

FiguRE 11. Change of profit function in (\%) w.r.t $M$.

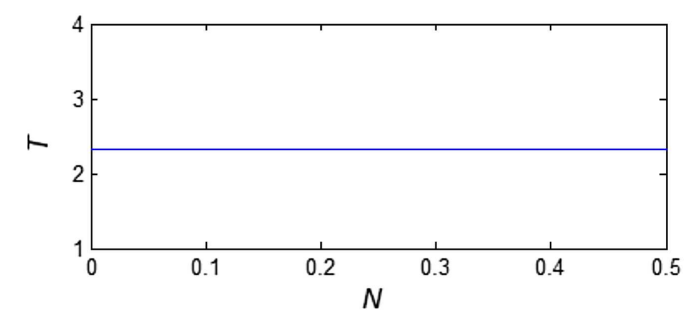

(a)

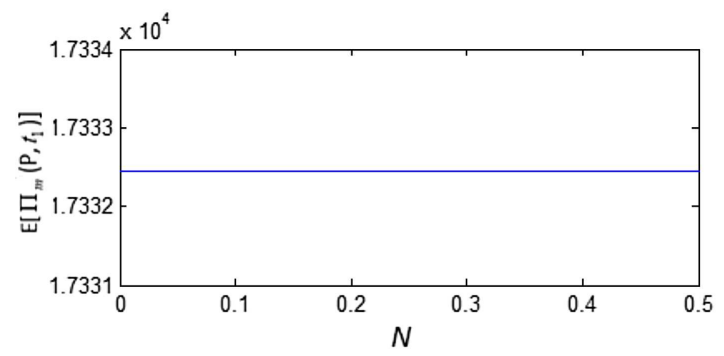

(c)

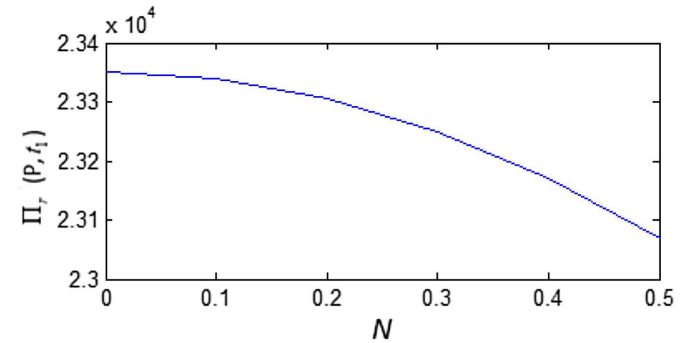

(b)

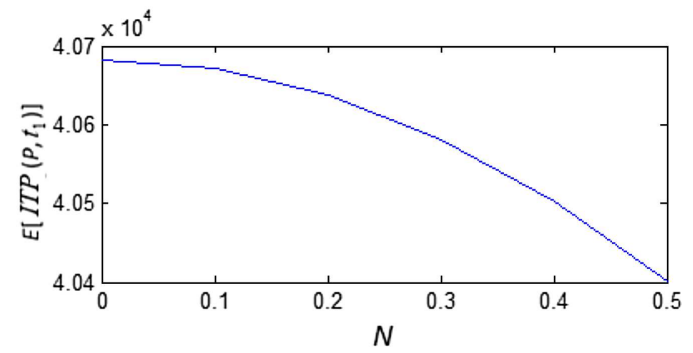

(d)

FiguRE 12. Graph w.r.t $N$.

Hence, per unit production cost for the manufacturer also increases. Obviously, the manufacturer reduces the production-run time because an increase in production-run time also increases the production of defective items. Again, more defective items indicate a poor manufacturing system and this image may not be a good sign for a manufacturing system. So, the manufacturer must be careful about the production of quality products. Thus, the parameter $\eta$ is very sensitive for the system.

(ix) Again, an increasing value of $\delta$ goes in favor of the system and also, production rate and production cost decrease with the increase in $\delta$ ( $c f$. Tab. 7). This means that if the manufacturer is able to transform the maximum number of defective items to perfect items, he can sell these items as perfect items. Hence, he has not to face more losses though the production system produces more defective items. But, the manufacturer has to spend a cost for the reworking purpose and also, this process may take much time. 


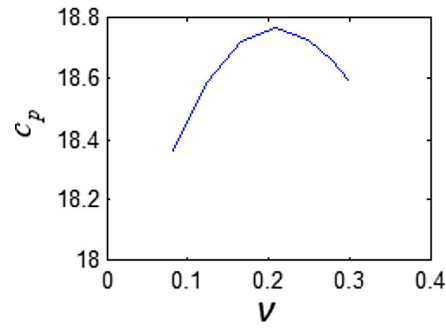

(a)

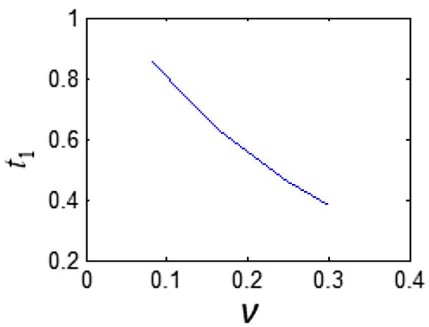

(c)

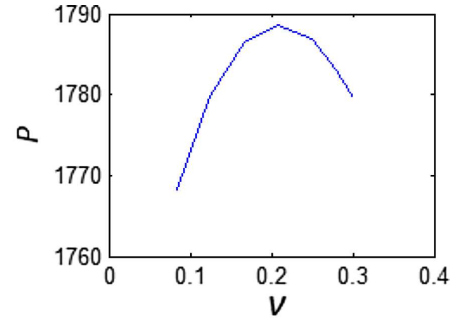

(b)

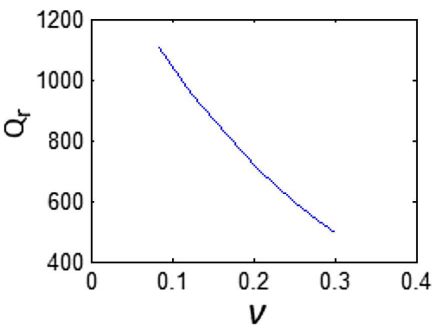

(d)

Figure 13. (a) $\nu$ vs. $c_{p}$, (b) $\nu$ vs. $P$, (c) $\nu$ vs. $t_{1}$, (d) $\nu$ vs. $Q_{r}$.

The manufacturer should look at the quality of production so that he can easily overcome such type of burden.

(x) Also, the higher value of $\gamma$ i.e., an increase in the number of disposal quantity reduces the optimal values $c_{p}, P, t_{1}, t_{2}, T$ and the integrated system's profit. Now, if a product has more defects, the product cannot be sold as a less imperfect quality item or converted into a perfect one. Therefore, if most of the imperfect items are treated as disposal items, the manufacturer does not earn from these items and on the other hand, he has to bear a cost for disposal. Therefore, the changes in optimal values regarding the parameter $\gamma$ are natural.

(xi) Table 7 shows that with increase in the index parameter $\nu$ for the production rate in defective rate parameter, optimal production rate first increases and then slowly decreases and hence, optimal production cost shows the same phenomenon. But, the manufacturer's production-run time and ordered lot-size of the distributor gradually decrease. This scenario is shown in Figure 13. Now, though the optimal production rate shows concave nature with increasing value of $\nu$, but the higher value of $\nu$ does not mean that the whole system is profitable due to very small production-run time. This scenario reflects that the manufacturer needs to focus on the impact of production rate on imperfect production.

(xii) With increase in effectiveness parameter $\mu$ in the production cost function, optimal production rate and production cost decreases which is quite normal. But, a very high value of $\mu$ increases the production-run time and reduces the total business cycle length. Table 7 also depicts that very low and very high value of $\mu$ both are benefited for the manufacturer's business system (cf. Fig. 14). But, the distributor's and also the integrated system's profit gradually decreases with $\mu$. Thus, it can be concluded that the manufacturer must observe the fact how the production cost will be affected by the production rate so that he can meet the market demand by optimizing the production rate.

(xiii) Figure 15a plots the graph of centroid value $\left(M^{*}\right)$ of $\widetilde{\widetilde{M}}$ with respect to $\Delta_{1}$ and $\Delta_{2}$. From this figure, it is reflected that value of $M^{*}$ increases slowly with the increasing value of $\Delta_{2}$ keeping $\Delta_{1}$ as fixed. But, converse nature is seen with respect to $\Delta_{1}$ keeping $\Delta_{2}$ as fixed which is depicted in Figure 15b.

Again, from Figure 16, it is observed that the value of $M^{*}$ gradually decreases with the increase in $\Delta_{3}$ keeping $\Delta_{4}$ as fixed and $M^{*}$ gradually increases with respect to $\Delta_{4}$ keeping $\Delta_{3}$ as fixed. This nature 


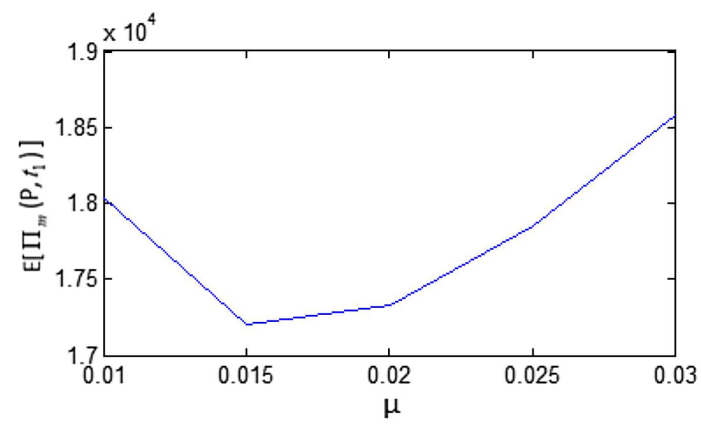

Figure 14. $\mu$ vs. $E\left[\Pi_{m}\left(P, t_{1}\right)\right]$.

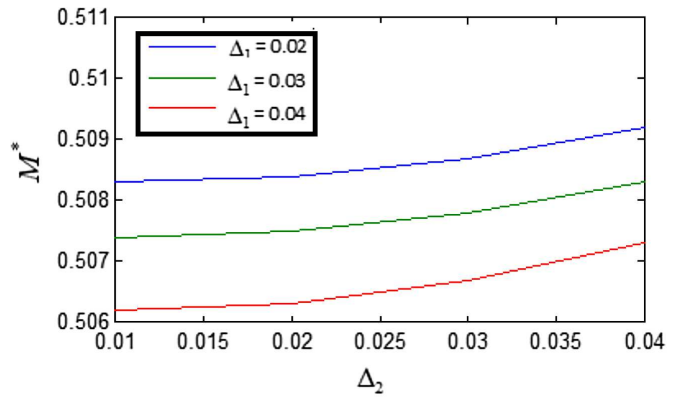

(a)

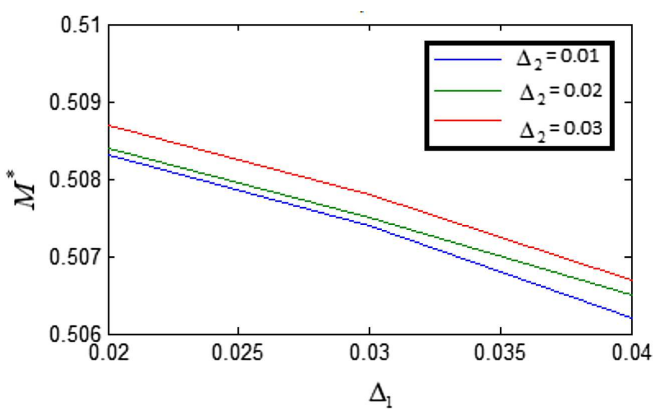

(b)

Figure 15. (a) $\Delta_{2}$ vs. $M^{*}$, (b) $\Delta_{1}$ vs. $M^{*}$.

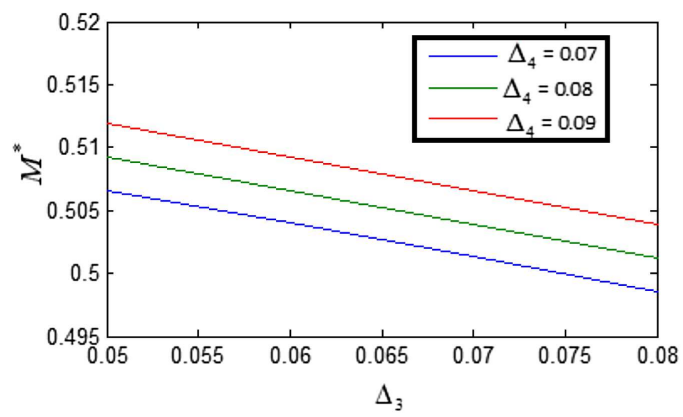

(a)

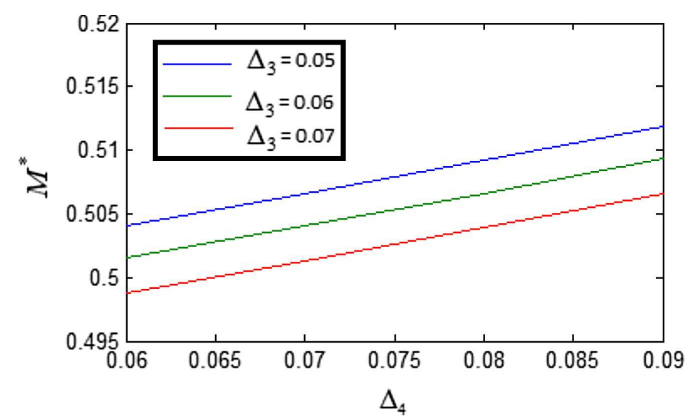

(b)

Figure 16 . (a) $\Delta_{3}$ vs. $M^{*}$, (b) $\Delta_{4}$ vs. $M^{*}$.

concludes that fluttering of the credit period $\widetilde{\widetilde{M}}$ from its ground level can be handled with increasing or decreasing the right or left spread.

(xiv) Table 8 analyzes the different results with respect to left and right spreads $\Delta_{1}, \Delta_{2}, \Delta_{3}$ and $\Delta_{4}$. From this table, it is seen that for a fixed value of $\Delta_{1}$, the optimal values of $c_{p}, P$ decreases with increase in $\Delta_{2}$ and the total business cycle length slowly decreases though optimal production run-time near about same. Again, the optimal profit $\mathrm{CV}_{\text {ITP }}$ decreases with respect to $\Delta_{2}$. But, the manufacturer's profit slowly increases as the value of $M^{*}$ increases. This phenomena is same as the crisp result for $M$. Thus, it can be 
said that by increasing the value of $M^{*}$, the manufacturer would be profitable, but the integrated system would be less profitable. Now, for a fixed value of $\Delta_{2}$, converse phenomena is shown with increase in $\Delta_{1}$.

Again, the same scenario like above will be occurred with increase in $\Delta_{4}$ keeping $\Delta_{3}$ fixed and converse. Thus, it can be concluded that increase of right spread $\Delta_{2}$ or $\Delta_{4}$ indicates less profit for the integrated system but more profit in respect of manufacturer.

\section{Conclusion And Future scopes}

In this article, a supply chain model for a manufacturer and a distributor is developed in an infinite time horizon. The manufacturer's production process goes to an "out-of-control" state after a random time and hence, produces imperfect as well as perfect items. Also here, it is considered that some imperfect items are restored in perfect quality by reworked and the rework process is error free. A percentage of imperfect items is marketable which are sold to another wholesale market at the end of the production process and the remaining portions are treated as disposal items. The production cost and the rate of imperfect production are assumed depending on the production rate. But, the selling price of perfect items is set as fixed comparing the market price of the items. Further, the distributor enjoys the facility of credit period for the total ordered quantity and hence, the credit period dependent demand rate is considered for the distributor. Also, the market demand rate of perfect items increases depending on stock of items at the distribution center. That means, more credit length for the distributor actually increase the market demand. Therefore, the important point is how long the system works to stock the items to sustain the system's profit due to the existence of these different demand structures. The novelty of this paper is that this study analyzes the adjustment of this two-type of demand to optimize the system's profit in integrating approach by optimizing production rate and production-run time. Again, due to the uncertainty of the real world, this model is discussed in fuzzy scenario assuming the credit length of the distributor in type-2 fuzzy sense. This model also considers a trade credit facility which is offered by the distributor.

Now, this model analyzes that though more credit length increases the demands, but Case 1 is most outfits for the system. That means, offering less credit period for both of the manufacturer and the distributor is more helpful to get the maximum profit of the whole system. Also, it is analyzed that less optimum production-run time whereas a longer total business period is most effective to sustain the system's profit in this situation due to variability in imperfect production. Again, this study shows an important and contradict nature for the credit length which is offered by the manufacturer. Generally, more credit length implies more opportunity loss for a manufacturer which may not indicate more profit to the manufacturer. Now, here, it is observed that more credit period is profitable for the manufacturer, but it is not indicated more profit for the integrating system. Again, the analysis with respect to the index parameter $\nu$ to the imperfectness of production shows the concave nature of optimum production rate but the system's profit gradually decreases. Thus the manufacturer has to focus to decide the value of this parameter. In the fuzzy model, this study shows that the system's profit decreases with increase in right spread keeping left spread as fixed and the converse nature is shown with increase in left spread keeping right spread as fixed. Also, from the analysis, it can be concluded that length of the credit period of the distributor can be handled easily by increasing or decreasing the left or right spread.

Again, there is another credit length for the customers which has no important influences in the business system. Thus, this study can be structured with new features of this credit length in future. Also, this study considerers $100 \%$ perfect screening process for the imperfect production process. But, sometimes the screening process may not be $100 \%$ accurate due to different difficulties in the screening process. So, this study can be extended with inspection errors in the screening process. Now, as the rate of imperfect production depends on production rate, so higher production rate may transfer the "in-control" state to the "out-of-control" state earlier. Hence, shifting time may depend on the production rate. Therefore, in future research, this study can be extended with the production rate dependent density function of the random shifting time. Again, in this study, it is considered that the rate of imperfect production linearly depends on the production-run length in the 
"out-of-control" state. So, one can study the rate of imperfect production with non-linearity in production-run length.

\section{Appendix A.}

Preliminaries: Here, some basic concepts about fuzzy set related to the paper are stated.

Definition A.1. Let $X$ be domain set. If $\tilde{A}$ is a fuzzy subset of $X$, for any $x \in X$

$$
\mu_{\tilde{A}}: X \rightarrow[0,1]
$$

$\mu_{\tilde{A}}$ is called a membership function of $x$ with respect to $\tilde{A}, \mu_{A}(x)$ denotes the grade to each point in $X$ with a real number in the interval $[0,1]$ that represents the grade of membership of $x$ in $A$. $\tilde{A}$ is called a fuzzy set and describe as follows

$$
\tilde{A}=\left\{\left(x, \mu_{A}(x)\right) \mid x \in X\right\} .
$$

This set also known as type-1 fuzzy set.

Definition A.2. A type-2 fuzzy set $\widetilde{\widetilde{A}}$ on $X$ is also a fuzzy set whose membership grades are also fuzzy on $[0,1]$ and defined as

$$
\widetilde{\widetilde{A}}=\left\{\left(x, \mu_{\tilde{A}}(x)\right): \mu_{\tilde{A}} \in \tilde{B}([0,1]), x \in X\right\}
$$

where $\tilde{B}([0,1])$ is a fuzzy set and $X$ is known as primary domain and $[0,1]$ is known as secondary domain.

Definition A.3. A fuzzy number $\tilde{M}$ is a convex normalized fuzzy set $\tilde{M}$ of the real line $\Re$ such that

(i) It exists exactly one $x_{0} \in \Re$ with $\mu_{\tilde{M}}\left(x_{0}\right)=1\left(x_{0}\right.$ is called the mean value of $\left.\tilde{M}\right)$.

(ii) $\mu_{\tilde{M}}(x)$ is piece wise continuous.

Definition A.4. Let $X$ be a cartesian product of universes $X=X_{1}, X_{2}, \ldots, X_{r}$ and $\tilde{A}_{1}, \tilde{A}_{2}, \ldots, \tilde{A}_{r}$ be fuzzy sets in $X=X_{1}, X_{2}, \ldots, X_{r}$ respectively. Assume that $f$ is a mapping from $X$ to a universe $Y, y=f\left(x_{1}, x_{2}, \ldots, x_{r}\right)$. Then the extension principle allows us to define a fuzzy set $B$ in $Y$ by

$$
\tilde{B}=\left(y, \mu_{\tilde{B}}(y)\right): y=f\left(x_{1}, x_{2}, \ldots, x_{r}\right),\left(x_{1}, x_{2}, \ldots, x_{r}\right) \in X
$$

where,

$$
\mu_{\tilde{B}}(y)= \begin{cases}\sup _{x \in f^{-1}(y)} \mu_{\tilde{A}}(x) ; & \text { if } f^{-1}(y) \neq \phi \\ 0 ; & \text { otherwise. }\end{cases}
$$

\section{Appendix B.}

The expansion of $\mu_{\widetilde{M}}(x)$ is derived as follows:

When $M_{0}-\Delta_{3} \leq x \leq M_{0}-\Delta_{1}$

In this domain from Figure 3 , it is clear that $\mu_{\mathrm{LMF}}(x)=0$ and $\mu_{\mathrm{UMF}}(x)=\frac{\left\{x-M_{0}+\Delta_{3}\right\} w_{2}}{\Delta_{3}}$. Therefore, the membership function $\mu_{\tilde{M}}(x)$ of TRS is given by

$$
\mu_{\widetilde{M}}(x)=\frac{\left\{x-M_{0}+\Delta_{3}\right\} w_{2}}{2 \Delta_{3}} .
$$


When $M_{0}-\Delta_{1} \leq x \leq M_{0}$

In this situation, Figure 3 reflects that $\mu_{\mathrm{LMF}}(x)=\frac{\left\{x-M_{0}+\Delta_{1}\right\} w_{1}}{\Delta_{1}}$ and $\mu_{\mathrm{UMF}}(x)=\frac{\left\{x-M_{0}+\Delta_{3}\right\} w_{2}}{\Delta_{3}}$. Hence, the membership function is given by

$$
\begin{aligned}
\mu_{\widetilde{M}}(x) & =\frac{1}{2}\left[\frac{\left\{x-M_{0}+\Delta_{1}\right\} w_{1}}{\Delta_{1}}+\frac{\left\{x-M_{0}+\Delta_{3}\right\} w_{2}}{\Delta_{3}}\right] \\
& =\frac{1}{2}\left[\frac{\left(x-M_{0}\right)}{\Delta_{1} \Delta_{3}}\left(\Delta_{3} w_{1}+\Delta_{1} w_{2}\right)+\left(w_{1}+w_{2}\right)\right] .
\end{aligned}
$$

When $M_{0} \leq x \leq M_{0}+\Delta_{2}$

In this domain, we see that $\mu_{\mathrm{LMF}}(x)=\frac{\left\{M_{0}+\Delta_{2}-x\right\} w_{1}}{\Delta_{2}}$ and $\mu_{\mathrm{UMF}}(x)=\frac{\left\{M_{0}+\Delta_{4}-x\right\} w_{2}}{\Delta_{4}}$. So, the membership function of the TRS is given below

$$
\begin{aligned}
\mu_{\widetilde{M}}(x) & =\frac{1}{2}\left[\frac{\left\{M_{0}+\Delta_{2}-x\right\} w_{1}}{\Delta_{2}}+\frac{\left\{M_{0}+\Delta_{4}-x\right\} w_{2}}{\Delta_{4}}\right] \\
& =\frac{1}{2}\left[\frac{\left(M_{0}-x\right)}{\Delta_{2} \Delta_{4}}\left(\Delta_{4} w_{1}+\Delta_{2} w_{2}\right)+\left(w_{1}+w_{2}\right)\right] .
\end{aligned}
$$

When $M_{0}+\Delta_{2} \leq x \leq M_{0}+\Delta_{4}$

In this domain, Figure 3 shows that $\mu_{\mathrm{LMF}}(x)=0$ and $\mu_{\mathrm{UMF}}(x)=\frac{\left\{M_{0}+\Delta_{4}-x\right\} w_{2}}{\Delta_{4}}$. Hence, the membership function $\mu_{\widetilde{M}}(x)$ of the TRS is as follows

$$
\mu_{\widetilde{M}}(x)=\frac{\left\{M_{0}+\Delta_{4}-x\right\} w_{2}}{2 \Delta_{4}} .
$$

Now, combining the expressions of $\mu_{\widetilde{M}}(x)$ in equations (B.1)-(B.4), we will get the membership function $\mu_{\widetilde{M}}(x)$ of the TRS.

\section{Appendix C.}

Derivation of the values of $\int_{-\infty}^{\infty} x \mu_{\widetilde{M}}(x) \mathrm{d} x$ and $\int_{-\infty}^{\infty} \mu_{\widetilde{M}}(x) \mathrm{d} x$ are shown in below:

$$
\begin{aligned}
\int_{-\infty}^{\infty} x \mu_{\widetilde{M}}(x) \mathrm{d} x= & \int_{M_{0}-\Delta_{3}}^{M_{0}-\Delta_{1}} x \frac{\left(x-M_{0}+\Delta_{3}\right) w_{2}}{2 \Delta_{3}} \mathrm{~d} x+\int_{M_{0}-\Delta_{1}}^{M_{0}} \frac{x}{2}\left[\frac{\left(x-M_{0}\right)}{\Delta_{1} \Delta_{3}}\left(\Delta_{3} w_{1}+\Delta_{1} w_{2}\right)+\left(w_{1}+w_{2}\right)\right] \mathrm{d} x \\
& +\int_{M_{0}}^{M_{0}+\Delta_{2}} \frac{x}{2}\left[\frac{\left(M_{0}-x\right)}{\Delta_{2} \Delta_{4}}\left(\Delta_{4} w_{1}+\Delta_{2} w_{2}\right)+\left(w_{1}+w_{2}\right)\right] \mathrm{d} x+\int_{M_{0}+\Delta_{2}}^{M_{0}+\Delta_{4}} x \frac{\left(M_{0}+\Delta_{4}-x\right) w_{2}}{2 \Delta_{4}} \mathrm{~d} x \\
= & \frac{\Delta_{1}+\Delta_{2}}{12}\left(3 M_{0}+\Delta_{2}-\Delta_{1}\right) w_{1}+\frac{\Delta_{3}+\Delta_{4}}{12}\left(3 M_{0}+\Delta_{4}-\Delta_{3}\right) w_{2} \\
= & \frac{1}{12}\left[w_{1}\left\{\left(M_{0}+\Delta_{2}\right)-\left(M_{0}-\Delta_{1}\right)\right\}\left\{\left(M_{0}+\Delta_{2}\right)+M_{0}+\left(M_{0}-\Delta_{1}\right)\right\}\right. \\
& \left.+w_{2}\left\{\left(M_{0}+\Delta_{4}\right)-\left(M_{0}-\Delta_{3}\right)\right\}\left\{\left(M_{0}+\Delta_{4}\right)+M_{0}+\left(M_{0}-\Delta_{3}\right)\right\}\right]
\end{aligned}
$$

and

$$
\begin{aligned}
\int_{-\infty}^{\infty} \mu_{\widetilde{M}}(x) \mathrm{d} x= & \int_{M_{0}-\Delta_{3}}^{M_{0}-\Delta_{1}} \frac{\left(x-M_{0}+\Delta_{3}\right) w_{2}}{2 \Delta_{3}} \mathrm{~d} x+\int_{M_{0}-\Delta_{1}}^{M_{0}} \frac{1}{2}\left[\frac{\left(x-M_{0}\right)}{\Delta_{1} \Delta_{3}}\left(\Delta_{3} w_{1}+\Delta_{1} w_{2}\right)+\left(w_{1}+w_{2}\right)\right] \mathrm{d} x \\
& +\int_{M_{0}}^{M_{0}+\Delta_{2}} \frac{1}{2}\left[\frac{\left(M_{0}-x\right)}{\Delta_{2} \Delta_{4}}\left(\Delta_{4} w_{1}+\Delta_{2} w_{2}\right)+\left(w_{1}+w_{2}\right)\right] \mathrm{d} x+\int_{M_{0}+\Delta_{2}}^{M_{0}+\Delta_{4}} \frac{\left(M_{0}+\Delta_{4}-x\right) w_{2}}{2 \Delta_{4}} \mathrm{~d} x
\end{aligned}
$$




$$
\begin{aligned}
& =\frac{w_{1}}{4}\left(\Delta_{1}+\Delta_{2}\right)+\frac{w_{2}}{4}\left(\Delta_{3}+\Delta_{4}\right) \\
& =\frac{w_{1}}{4}\left\{\left(M_{0}+\Delta_{2}\right)-\left(M_{0}-\Delta_{1}\right)\right\}+\frac{w_{2}}{4}\left\{\left(M_{0}+\Delta_{4}\right)-\left(M_{0}-\Delta_{3}\right)\right\} .
\end{aligned}
$$

\section{Appendix D.}

Taking $\xi=1$, approximations of $E\left[\left(t_{1}-\tau\right)^{2}\right]$ and $E\left[\left(t_{1}-\tau\right)^{3}\right]$ are given below:

$$
\begin{aligned}
\int_{0}^{t_{1}}\left(t_{1}-\tau\right)^{2} f(\tau) \mathrm{d} \tau & =\lambda \int_{0}^{t_{1}}\left(t_{1}-\tau\right)^{2} e^{-\lambda \tau} \mathrm{d} \tau \\
& =t_{1}^{2}-\frac{2 t_{1}}{\lambda}+\frac{2}{\lambda^{2}}\left\{1-e^{-\lambda t_{1}}\right\} \\
& =\frac{1}{3} \lambda t_{1}^{3} \text {, approximating up to the fourth term of the expansion of } e^{-\lambda t_{1}} \\
\int_{0}^{t_{1}}\left(t_{1}-\tau\right)^{3} f(\tau) \mathrm{d} \tau & =\lambda \int_{0}^{t_{1}}\left(t_{1}-\tau\right)^{3} e^{-\lambda \tau} \mathrm{d} \tau \\
& =t_{1}^{3}-3 \int_{0}^{t_{1}}\left(t_{1}-\tau\right)^{2} e^{-\lambda \tau} \mathrm{d} \tau \\
& =t_{1}^{3}-\frac{3}{\lambda} \int_{0}^{t_{1}}\left(t_{1}-\tau\right)^{2} f(\tau) \mathrm{d} \tau \\
& =t_{1}^{3}-\frac{3}{\lambda}\left[t_{1}^{2}-\frac{2 t_{1}}{\lambda}+\frac{2}{\lambda^{2}}\left\{1-e^{-\lambda t_{1}}\right\}\right] \\
& =\frac{1}{4} \lambda t_{1}^{4}, \text { approximating up to the fifth term of the expansion of } e^{-\lambda t_{1}} .
\end{aligned}
$$

Acknowledgements. The authors express their sincere thanks to the editor and the anonymous reviewers for their valuable comments and suggestions which have led to a significant improvement of the manuscript. The second author would like to thank University Grants Commission for providing the Dr. D. S. Kothari Post-Doctoral Fellowship (DSKPDF) through The University of Burdwan to accomplish this research (Vide Research Grant No.F.4-2/2006 (BSR)/MA/18-19/0023).

\section{REFERENCES}

[1] S.P. Aggarwal and C.K. Jaggi, Ordering policies of deteriorating items under permissible delay in payments. J. Oper. Res. Soc. 46 (1995) 658-662.

[2] A. Banu and S.K. Mondal, Analyzing an inventory model with two-level trade credit period including the effect of customers' credit on the demand function using $q$-fuzzy number. Oper. Res. Int. J. 20 (2020) 1559-1587.

[3] A. Banu and S.K. Mondal, An integrated inventory model with warranty dependent credit period under two policies of a manufacturer. Opsearch 55 (2018) 677-702.

[4] K.J. Chung and L.E. Cárdenas-Barrón, The simplified solution procedure for deteriorating items under stock-dependent demand and two-level trade credit in the supply chain management. Appl. Math. Model. 37 (2013) 4653-4660.

[5] B.C. Das, B. Das and S.K. Mondal, Integrated supply chain model for a deteriorating item with procurement cost dependent credit period. Comput. Ind. Eng. 64 (2013) 788-796.

[6] B.C. Das, B. Das and S.K. Mondal, Optimal transportation and business cycles in an integrated production inventory model with a discrete credit period. Transport. Res. E-Log. 68 (2014) 1-13.

[7] B.C. Das, B. Das and S.K. Mondal, An integrated production inventory model under interactive fuzzy credit period for deteriorating item with several markets. Appl. Soft. Comput. 28 (2015) 435-465.

[8] C.Y. Dye and L.Y. Ouyang, A particle swarm optimization for solving joint pricing and lot-sizing problem with flactuating demand and trade credit financing. Comput. Ind. Eng. 60 (2011) 127-137.

[9] B.C. Giri and T. Dohi, Inspection scheduling for imperfect production process under free repair warranty contract. Eur. J. Oper. Res. 183 (2007) 238-252.

[10] S.K. Goyal, Economic order quanity under conditions of permissible delay in payments. J. Oper. Res. Soc. 36 (1985) $335-338$.

[11] S.K. Goyal and A. Gunasekaran, An integrated production-inventorymarketing model for deteriorating items. Comput. Ind. Eng. 28 (1995) 755-762.

[12] F.W. Harris, Operations and Cost, Factory Management Series. A.W. Shaw Co. (1915). 
[13] K.L. Hou, An EPQ model with setup cost and process quality as functions of capital expenditure. Appl. Math. Model. 31 (2007) 10-17.

[14] Y.F. Huang, Optimal retailer's ordering policies in the EOQ model under trade credit financing. J. Oper. Res. Soc. 54 (2003) 1011-1015.

[15] M. Karimi-Nasab and K. Sabri-Laghaie, Developing approximate algorithms for EPQ problem with process compressibility and random error in production inspection. Int. J. Prod. Res. 52 (2014) 2388-2421.

[16] N. Kazemi, S.H. Abdul-Rashid, E. Shekarian, E. Bottani and R. Montanari, A fuzzy lot-sizing problem with two-stage composite human learning. Int. J. Prod. Res. 54 (2016) 5010-5025.

[17] M. Khan, M.Y. Jaber, A.L. Guiffrida and S. Zolfaghari, A review of the extensions of a modified EOQ model for imperfect quality items. Int. J. Prod. Econ. 132 (2011) 1-12.

[18] J.J. Liao, An EOQ model with non-instantaneous receipt and exponentially deteriorating items under two-level trade credit. Int. J. Prod. Econ. 113 (2008) 852-861.

[19] P. Mandal and B.C. Giri, A two-warehouse integrated inventory model with imperfect production process under stockdependent demand and quantity discount offer. Int. J. Syst. Sci. 6 (2019) 15-26.

[20] A.K. Manna, J.K. Dey and S.K. Mondal, Imperfect production inventory model with production rate dependent defective rate and advertisement dependent demand. Comput. Ind. Eng. 104 (2017) 9-22.

[21] A.K. Manna, J.K. Dey and S.K. Mondal, Two layers green supply chain imperfect productioninventory model under bi-level credit period. Tekhne 15 (2017) 124-142.

[22] A.K. Manna, B. Das and S. Tiwari, Impact of carbon emission on imperfect production inventory system with advance payment base free transportation. RAIRO: OR 54 (2020) 1103-1117.

[23] A.K. Manna, J.K. Dey and S.K. Mondal, Effect of inspection errors on imperfect production inventory model with warranty and price discount dependent demand rate. RAIRO: OR 54 (2020) 1189-1213.

[24] S. Panja and S.K. Mondal, Analyzing a four-layer green supply chain imperfect production inventory model for green products under type-2 fuzzy credit period. Comput. Ind. Eng. 129 (2019) 435-453.

[25] M.J. Rosenblatt and H.L. Lee, Economic production cycles with imperfect production processes. IIE Trans. 18 (1986) $48-55$.

[26] M.K. Salameh and M.Y. Jaber, Economic production quantity model for items with imperfect quality. Int. J. Prod. Econ. 64 (2000) 59-64.

[27] S.S. Sana, An economic production lot size model in an imperfect production system. Eur. J. Oper. Res. 201 (2010) 158-170.

[28] E.A. Silver and R. Peterson, Decision Systems for Inventory Management and Production Planning, 2nd edition. Wiley, New York (1985).

[29] N.H. Shah and L.E. Cardenas-Barron, Retailer's decision for ordering and credit policies for deteriorating items when a supplier offers order-linked credit period or cash discount. Appl. Math. Comput. 259 (2015) 569-573.

[30] E. Shekarian, C.H. Glock, S.M.P. Amiri and K. Schwindl, Optimal manufacturing lot size for a single-stage production system with rework in a fuzzy environment. J. Intell. Fuzy. Syst. 27 (2014) 3067-3080.

[31] E. Shekarian, M.Y. Jaber, N. Kazemi and E. Ehsani, A fuzzifed version of the economic production quantity (EPQ) model with backorders and rework for a single-stage system. Eur. J. Ind. Eng. 8 (2014) 291-324.

[32] E. Shekarian, E.U. Olugu, S.H. Abdul-Rashid and N. Kazemi, Analyzing optimization techniques in inventory models: the case of fuzzy economic order quantity problems. In: Proceedings of Conference on Industrial Engineering and Operations Management, Kuala Lumpur, Malaysia, March 8-10 (2016) 1229-1240.

[33] E. Shekarian, N. Kazemi, S.H. Abdul-Rashid and E.U. Olugu, Fuzzy inventory models: a comprehensive review. Appl. Soft. Comput. 55 (2017) 588-621.

[34] A.A. Taleizadeh, H.M. Wee and F. Jolai, Revisiting a fuzzy rough economic order quantity model for deteriorating items considering quantity discount and prepayment. Math. Comput. Model. 57 (2013) 1466-1479.

[35] Y.C. Taso, Determination of production run time and warranty length under system maintenance and trade credits. Int. J. Syst. Sci. 43 (2012) 2312-2360.

[36] J.T. Teng, On the economic order quantity under conditions of permissible delay in payments. J. Oper. Res. Soc. 53 (2002) 915-918.

[37] H.J. Zimmermann, Fuzzy Set Theory and Its Applications, 2nd revised edition. Kluwer Academic Publishers, Dordrecht, The Netherlands (1991). 